\title{
๖The Numerical Implementation of Land Models: Problem Formulation and Laugh Tests
}

\author{
Martyn P. Clark, ${ }^{\mathrm{a}, \mathrm{b}}$ Reza Zolfaghari,${ }^{\mathrm{c}}$ Kevin R. Green, ${ }^{\mathrm{c}}$ Sean Trim, ${ }^{\mathrm{c}}$ Wouter J. M. Knoben, ${ }^{\mathrm{a}}$ \\ ANDREW BENNETT, ${ }^{\mathrm{d}}$ BART NIJSSEN, ${ }^{\mathrm{d}}$ ANDREW IRESON, ${ }^{\mathrm{e}}$ AND RAYMOND J. SPITERI ${ }^{\mathrm{c}}$ \\ ${ }^{\text {a }}$ Centre for Hydrology, University of Saskatchewan, Canmore, Alberta, Canada \\ ${ }^{\mathrm{b}}$ Department of Geography and Planning, University of Saskatchewan, Saskatoon, Saskatchewan, Canada \\ ${ }^{\mathrm{c}}$ Department of Computer Science, University of Saskatchewan, Saskatoon, Saskatchewan, Canada \\ ${ }^{\mathrm{d}}$ Department of Civil and Environmental Engineering, University of Washington, Seattle, Washington \\ ${ }^{\mathrm{e}}$ Global Institute for Water Security, University of Saskatchewan, Saskatoon, Saskatchewan, Canada
}

(Manuscript received 17 July 2020, in final form 4 April 2021)

\begin{abstract}
The intent of this paper is to encourage improved numerical implementation of land models. Our contributions in this paper are twofold. First, we present a unified framework to formulate and implement land model equations. We separate the representation of physical processes from their numerical solution, enabling the use of established robust numerical methods to solve the model equations. Second, we introduce a set of synthetic test cases (the laugh tests) to evaluate the numerical implementation of land models. The test cases include storage and transmission of water in soils, lateral subsurface flow, coupled hydrological and thermodynamic processes in snow, and cryosuction processes in soil. We consider synthetic test cases as "laugh tests" for land models because they provide the most rudimentary test of model capabilities. The laugh tests presented in this paper are all solved with the Structure for Unifying Multiple Modeling Alternatives (SUMMA) model implemented using the Suite of Nonlinear and Differential/Algebraic Equation Solvers (SUNDIALS). The numerical simulations from SUMMA/SUNDIALS are compared against 1) solutions to the synthetic test cases from other models documented in the peer-reviewed literature, 2) analytical solutions, and 3) observations made in laboratory experiments. In all cases, the numerical simulations are similar to the benchmarks, building confidence in the numerical model implementation. We posit that some land models may have difficulty in solving these benchmark problems. Dedicating more effort to solving synthetic test cases is critical in order to build confidence in the numerical implementation of land models.
\end{abstract}

KEYWORDS: Diagnostics; Hydrologic models; Land surface model

\section{Introduction}

Land models encompass a broad class of models that are used to simulate biogeophysical processes (and sometimes biogeochemical processes) in terrestrial systems (e.g., Wigmosta et al. 1994; Baldocchi and Wilson 2001; Tague and Band 2004; Lawrence et al. 2019). Land models have varying degrees of spatial complexity and process complexity, with much focus on methods to represent spatial heterogeneity (e.g., Peters-Lidard et al. 2017; Fisher and Koven 2020) and parameterizations to represent the dominant biogeophysical and biogeochemical processes (e.g., Walker et al. 2015; Fatichi et al. 2016). Land models are used for a myriad of applications, including applications to simulate the terrestrial component of the Earth system (e.g., Lawrence et al. 2019), to provide a lower boundary condition for the atmosphere in numerical weather prediction models (e.g., Balsamo et al. 2011), to assess risks to water security (e.g., Wada et al. 2014), and to predict hydrological extremes (e.g., Wanders et al. 2019).

In the last decade, we have arguably seen a convergence across different land modeling communities. Land modeling is

¿ Denotes content that is immediately available upon publication as open access.

Corresponding author: Martyn P. Clark, martyn.clark@usask.ca inherently an interdisciplinary endeavor, requiring expertise from hydrologists, biogeochemists, ecologists, geologists, atmospheric scientists, applied mathematicians, and many other disciplines (e.g., Fisher and Koven 2020). Although different land models have evolved in different ways, land models developed by different communities now include a similar set of processes. Such convergence is creating new opportunities to collaborate across disciplines, to learn from each other, and to share insights across different modeling communities (e.g., Coon et al. 2016; Bisht and Riley 2019).

A key challenge is that the decades-long development of land models means that they have become rather unwieldy. Many land models have evolved to include a menagerie of physical processes that are cobbled together in haphazard ways: New representations of individual processes are typically "bolted on" to previous model versions, with new parameterizations of physical processes (e.g., flux parameterizations) closely intertwined with their numerical solutions (e.g., Clark et al. 2015b; Fisher and Koven 2020). This causes two key problems. First, it can be difficult to add new modeling capabilities when the existing model structure is disorganized. For example, as pointed out by Bisht and Riley (2019), the monolithic structure of land models makes it cumbersome to systematically isolate and evaluate individual process parameterizations (see also Clark et al. 2011, 2015b). The second problem with land models is that their numerical implementation often relies on an ad hoc collection of simplistic solution methods that are tied to individual 


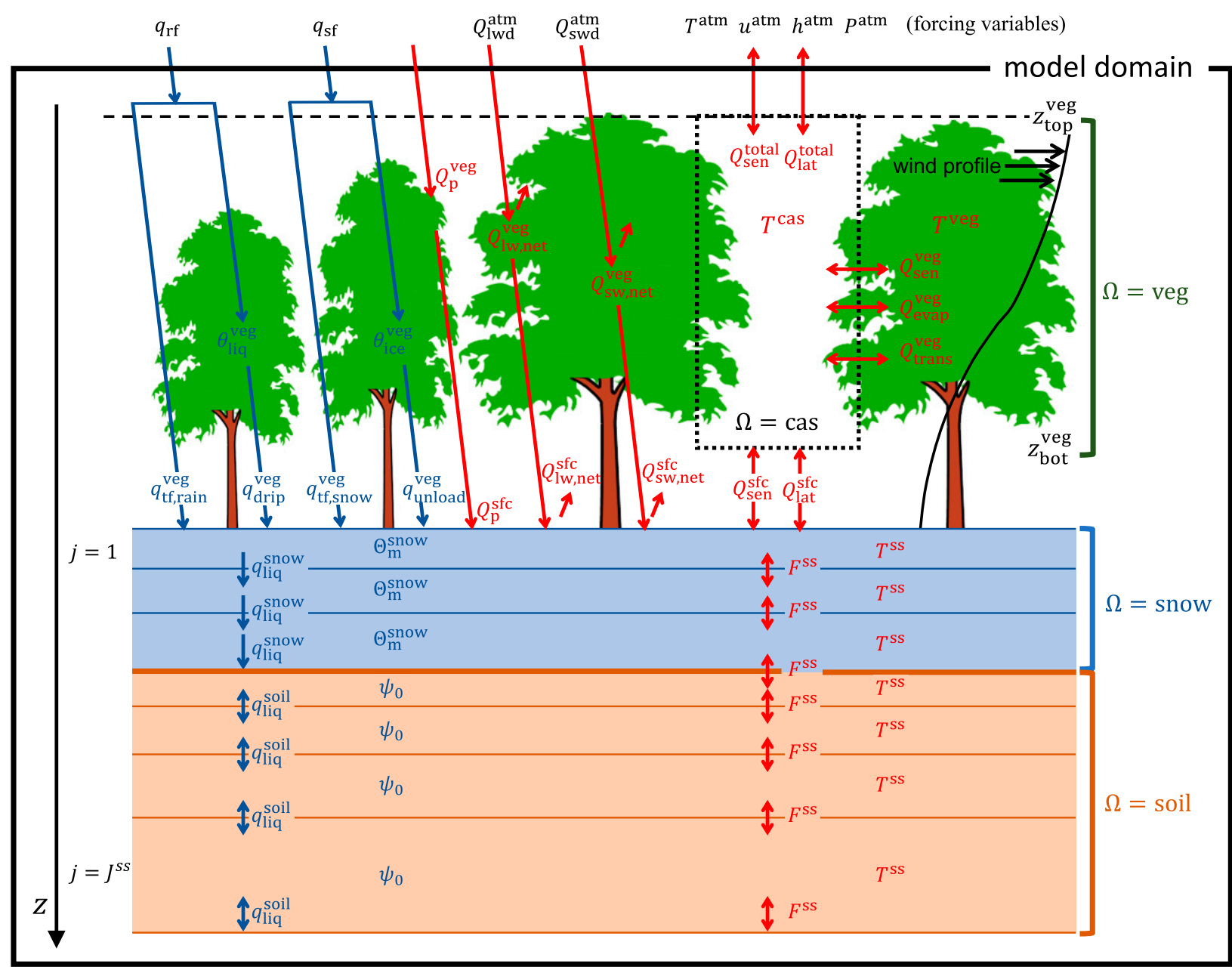

FIG. 1. Conceptual depiction of the dominant thermodynamical and hydrological processes solved in land models. The red and blue font define thermodynamic and hydrological processes respectively; the flux $q_{\mathrm{ice}}^{\Omega}$ in Eq. (2) is only defined in the vegetation and snow domains, and includes snowfall $q_{\mathrm{sf}}$, throughfall of snow through the vegetation canopy $q_{\mathrm{tf} \text {,snow }}^{\mathrm{veg}}$, and unloading of snow from the vegetation canopy $q_{\text {unload }}^{\text {veg }}$ The model forcing variables are snowfall $q_{\mathrm{sf}}\left(\mathrm{kg} \mathrm{m}^{-2} \mathrm{~s}^{-1}\right)$, rainfall $q_{\mathrm{rf}}\left(\mathrm{kg} \mathrm{m}^{-2} \mathrm{~s}^{-1}\right)$, downwelling shortwave radiation $Q_{\mathrm{swd}}^{\text {atm }}$ $\left(\mathrm{J} \mathrm{m}^{-2} \mathrm{~s}^{-1}\right)$, downwelling longwave radiation $Q_{\mathrm{lwd}}^{\text {atm }}\left(\mathrm{J} \mathrm{m}^{-2} \mathrm{~s}^{-1}\right)$, temperature, $T^{\mathrm{atm}}(\mathrm{K})$, wind speed $u^{\text {atm }}\left(\mathrm{m} \mathrm{s}^{-1}\right)$, specific humidity $h^{\text {atm }}$ $\left(\mathrm{kg} \mathrm{kg}^{-1}\right)$, and atmospheric pressure $p^{\text {atm }}(\mathrm{Pa})$. All other variables are defined in the text.

process representations (e.g., Bisht and Riley 2019). The underlying system of equations is rarely defined explicitly, and the details of the numerical implementation are often obscure [e.g., see the critique in Clark et al. (2015b)]. The failure to cleanly separate the model equations from their numerical solution makes it difficult for land modelers to benefit from more advanced numerical methods, such as the development of robust nonlinear equation solvers, adaptive time-stepping and temporal error control, and proper handling of discontinuities.

The intent of this paper is to encourage improved numerical implementation of land models. In our opinion, the implementation details of land models do not get the attention they deserve in the peer-reviewed literature. Such a lack of focus on model implementation can affect the credibility of land models. After all, the governing equations are the fundamental building blocks of land models-if the equations or the methods for their solution are not implemented correctly, then all predictions from such land models are suspect.

Our contributions in this paper are twofold. 1) We present a unified framework to formulate and implement land model equations [extending the work of Clark et al. (2015b,c)]. We separate the representation of physical processes from their numerical solution, enabling the use of established robust numerical methods to solve the model equations. 2) $\mathrm{We}$ introduce a set of synthetic test cases-the laugh tests-to evaluate the numerical implementation of land models. We make the inputs and outputs from the test cases publicly available so that other modeling groups can use the test cases in their own model development efforts. By presenting the equations, the numerical methods, and tractable test cases, our broader goal is to provide information in a form that is useful for both land modelers and applied mathematicians to improve the numerical implementation of land models. 
The remainder of this paper is organized as follows. Section 2 specifies the general equations solved in land models, the spatial approximations of the model equations, and the solution of the resulting ordinary differential equations. Section 3 describes the synthetic test cases and their solutions, and section 4 describes checks for the conservation of energy and mass. Section 5 describes the availability of the test case solutions and the code repository used to reproduce them. Section 6 concludes the paper with a summary and discussion.

\section{Land model equations: Description and numerical implementation}

In this section, we present a unified framework to formulate and implement land models. Our framework is limited to the terrestrial water and energy fluxes shown in Fig. 1 (see also Clark et al. 2015b). We do not include terrain effects on the radiation balance, vapor transport within snow and soil, or horizontal transport of snow associated with avalanching or drifting (e.g., Marsh et al. 2018), and we do not explicitly represent glaciers, depression storage, wetlands and lakes, major aquifers, losses from the stream to the aquifer, and human impacts on the terrestrial water cycle such as reservoir operations and irrigation (e.g., Bowling and Lettenmaier 2010; Fan and Miguez-Macho 2011; Miguez-Macho and Fan 2012; Li et al. 2013; Yigzaw et al. 2019).

From a land modeling perspective, our representation of vegetation is rather limited compared to modern land models (e.g., Lawrence et al. 2019). In particular, we do not include the storage and fluxes of carbon, nitrogen, and phosphorous (e.g., Zaehle and Friend 2010; Melton et al. 2020), and we do not explicitly simulate the pressure gradients throughout the soilwater-atmosphere continuum (e.g., Bonan et al. 2014; Mackay et al. 2015) that are necessary to simulate the cavitation of the xylem, delayed xylem infilling, and hence the memory in hydraulic dysfunction.

It is straightforward to extend these model equations to include these additional physical processes both through expanding model couplings (e.g., coupling with a groundwater model) or through expanding the current set of state equations. The limited implementation presented here is intended to provide an example of an extensible framework that can be adopted for multiple physical processes and process couplings.

\section{a. State equations}

Most land models solve a variant of the coupled conservation equations for thermodynamics and hydrology for the subdomains of the canopy air space (cas), vegetation (veg), snow, and soil (Fig. 1). The state equations for thermodynamics and hydrology can be written for a given model subdomain $\Omega$ as

$$
\begin{aligned}
& \frac{\partial H^{\Omega}}{\partial t}=-\frac{\partial F^{\Omega}}{\partial z}+\mathcal{F}_{\text {sink }}^{\Omega}, \Omega=\text { cas, veg, snow, soil }, \\
& \frac{\partial \Theta_{m}^{\Omega}}{\partial t}=-\frac{\partial q_{\mathrm{ice}}^{\Omega}}{\partial z}-\frac{\partial q_{\mathrm{liq}}^{\Omega}}{\partial z}+\mathcal{M}_{\text {sink }}^{\Omega}, \Omega=\text { veg, snow, soil },
\end{aligned}
$$

TABLE 1. Constituents for model subdomains.

\begin{tabular}{cl}
\hline \hline Subdomain & \multicolumn{1}{c}{ Constituents } \\
\hline cas & Air \\
veg & Stems, leaves, liquid water, ice, air \\
snow & Liquid water, ice, air \\
soil & Soil particles, liquid water, ice, air \\
\hline
\end{tabular}

where $H^{\Omega}\left(\mathrm{J} \mathrm{m}^{-3}\right)$ is the mixture enthalpy, $\Theta_{m}^{\Omega}(-)$ is the volumetric fraction of total water, $z(\mathrm{~m})$ is the vertical coordinate (positive downward), and $t$ (s) is time. The remaining terms on the RHS of Eqs. (1) and (2) are defined below.

In the development that follows, we link the temperature and enthalpy form of the heat equation in order to define conservative equations for thermodynamics. In land models the mixture enthalpy $H^{\Omega}$ is equal to the internal energy of the system (Tubini et al. 2020). The mixture enthalpy $H^{\Omega}$ is defined as (e.g., Voller et al. 1990; Nedjar 2002; Dall'Amico et al. 2011; Tubini et al. 2020)

$$
H^{\Omega}=\sum_{i} H_{T, i}^{\Omega}-L_{\text {fus }} \rho_{\text {ice }} \Delta \theta_{\text {ice }}^{\Omega},
$$

where $H_{T, i}^{\Omega}$ is the temperature component of the enthalpy of constituent $i$ (see Table 1 for the constituents of the model subdomains) and $L_{\text {fus }} \rho_{\text {ice }} \Delta \theta_{\text {ice }}^{\Omega}$ is the energy associated with melt/freeze, with $L_{\text {fus }}\left(\mathrm{J} \mathrm{kg}^{-1}\right)$ the latent heat of fusion and $\rho_{\text {ice }}$ $\left(\mathrm{kg} \mathrm{m}^{-3}\right)$ the intrinsic density of ice. The terms on the RHS of Eq. (3) are

$$
\begin{aligned}
& H_{T, i}^{\Omega}=c_{i} \rho_{i} \int_{T_{\mathrm{ref}}}^{T^{\Omega}} \theta_{i}^{\Omega} d T, \\
& \Delta \theta_{\mathrm{ice}}^{\Omega}=\theta_{\mathrm{ice}}^{\Omega}\left(T^{\Omega}\right)-\theta_{\mathrm{ice}}^{\Omega}\left(T_{\mathrm{ref}}\right),
\end{aligned}
$$

with $c_{i}\left(\mathrm{~J} \mathrm{~kg}^{-1} \mathrm{~K}^{-1}\right), \rho_{i}\left(\mathrm{~kg} \mathrm{~m}^{-3}\right)$, and $\theta_{i}^{\Omega}(-)$ the specific heat, the intrinsic density, and the volumetric fraction of constituent $i$, respectively, $T^{\Omega}(\mathrm{K})$ the temperature, with

$$
\sum_{i} \theta_{i}^{\Omega}=1
$$

The mixture enthalpy $H^{\Omega}$ in Eq. (3) is defined such that it is negative when the temperature is below the reference temperature and positive when the temperature is above the reference temperature (the reference temperature is often set to the freezing point). The mixture enthalpy $H^{\Omega}$ can be defined as a diagnostic variable computed from the state variables $T^{\Omega}$ and $\Theta_{m}^{\Omega}$.

The volumetric fraction of total water $\Theta_{m}^{\Omega}(-)$ is defined as

$$
\Theta_{m}^{\Omega}=\theta_{\text {liq }}^{\Omega}+\frac{\rho_{\text {ice }}}{\rho_{\text {liq }}} \theta_{\text {ice }}^{\Omega} .
$$

We note that no water is stored in the canopy air space, and hence the subdomains for Eq. (2) are restricted to $\Omega=$ veg, snow, soil.

The terms on the RHS of Eqs. (1) and (2) are defined as follows. In Eq. (1), $F^{\Omega}\left(T^{\Omega}, \Theta_{m}^{\Omega}\right)\left(\mathrm{J} \mathrm{m}^{-2} \mathrm{~s}^{-1}\right)$ is the vertical energy flux and $\mathcal{F}_{\text {sink }}^{\Omega}\left(T^{\Omega}, \Theta_{m}^{\Omega}\right)\left(\mathrm{J} \mathrm{m}^{-3} \mathrm{~s}^{-1}\right)$ is the source-sink flux 
term for energy; in Eq. (2), $q_{\mathrm{ice}}^{\Omega}\left(T^{\Omega}, \Theta_{m}^{\Omega}\right)\left(\mathrm{m} \mathrm{s}^{-1}\right)$ and $q_{\text {liq }}^{\Omega}\left(T^{\Omega}, \Theta_{m}^{\Omega}\right)$ $\left(\mathrm{m} \mathrm{s}^{-1}\right)$ are the vertical fluxes of solid and liquid water, and $\mathcal{M}_{\text {sink }}^{\Omega}\left(T^{\Omega}, \Theta_{m}^{\Omega}\right)\left(\mathrm{s}^{-1}\right)$ is the fractional source-sink flux term for hydrology. The source-sink flux terms are meant to capture physical processes that do not correspond to vertical fluxes, e.g., the transpiration sink term in soil hydrology associated with the latent heat flux. The vertical fluxes of solid water in Eq. (2), $q_{\mathrm{ice}}^{\Omega}$, include both snowfall (above the vegetation canopy) and throughfall and unloading of snow (within the vegetation canopy).

Many models separate the temperature change and phase change terms in Eq. (1) (see, e.g., Koren et al. 1999; Hansson et al. 2004; Clark et al. 2015b,c; Bao et al. 2016; Wang et al. 2017; Clow 2018). Using Eq. (3) in Eq. (1) results in

$$
\frac{\partial H_{T}^{\Omega}}{\partial t}-L_{\text {fus }} \rho_{\text {ice }} \frac{\partial \theta_{\text {ice }}^{\Omega}}{\partial t}=-\frac{\partial F^{\Omega}}{\partial z}+\mathcal{F}_{\text {sink }}^{\Omega},
$$

where

$$
H_{T}^{\Omega}=\sum_{i} H_{T, i}^{\Omega}
$$

Equation (1) can then be written as

$$
C_{p}^{\Omega} \frac{\partial T^{\Omega}}{\partial t}-L_{\text {fus }} \rho_{\text {ice }} \frac{\partial \theta_{\text {ice }}^{\Omega}}{\partial t}=-\frac{\partial F^{\Omega}}{\partial z}+\mathcal{F}_{\text {sink }}^{\Omega},
$$

where $C_{p}\left(\mathrm{~J} \mathrm{~m}^{-3}\right)$ is the volumetric heat capacity

$$
C_{p}^{\Omega}=\sum_{i} c_{i} \rho_{i} \theta_{i}^{\Omega}
$$

obtained by differentiating Eq. (4), i.e., $\partial H_{T, i}^{\Omega} / \partial T^{\Omega}=c_{i} \rho_{i} \theta_{i}^{\Omega}$, and accounting for the volumetric fraction of each of the $i$ constituents. The energy fluxes on the RHS of Eq. (10) are used to either change the temperature of the system (first term on the LHS) or for phase transition (second term on the LHS).

We note that Eq. (1) can also be formulated in terms of apparent heat capacity (e.g., Harlan 1973; Hansson et al. 2004):

$$
C_{a}^{\Omega} \frac{\partial T^{\Omega}}{\partial t}=-\frac{\partial F^{\Omega}}{\partial z}+\mathcal{F}_{\text {sink }}^{\Omega},
$$

where $C_{a}^{\Omega}\left(\mathrm{J} \mathrm{m}^{-3} \mathrm{~K}^{-1}\right)$ is the apparent heat capacity

$$
C_{a}^{\Omega}=\frac{\partial H^{\Omega}}{\partial T^{\Omega}}=C_{p}^{\Omega}-L_{\text {fus }} \rho_{\text {ice }} \frac{\partial \theta_{\text {ice }}^{\Omega}}{\partial T^{\Omega}} .
$$

In Eqs. (10)-(13), $\theta_{\mathrm{ice}}^{\Omega}$ is a diagnostic variable computed from $T^{\Omega}$ and $\Theta_{m}^{\Omega}$.

The conservation equation for hydrology defined in Eq. (2) is a general equation, and variants of Eq. (2) are used in most land models. There are, however, two important deviations from Eq. (2). First, the fluxes of water vapor in the canopy air space must be defined. The vapor fluxes can be defined as (Flerchinger et al. 1998; Bonan et al. 2018)

$$
\rho_{\text {air }} \frac{\partial \vartheta^{\text {cas }}}{\partial t}=-\frac{\partial}{\partial z}\left(\rho_{\text {air }} k_{e} \frac{\partial \vartheta^{\mathrm{cas}}}{\partial z}\right)+\frac{\mathcal{F}_{\mathrm{lat}}^{\mathrm{veg}}}{L_{\mathrm{vap}}}
$$

where $\vartheta^{\text {cas }}\left(\mathrm{kg} \mathrm{kg}^{-1}\right)$ is the specific humidity in the canopy air space, $L_{\mathrm{vap}}\left(\mathrm{J} \mathrm{kg}^{-1}\right)$ is the latent heat of vaporization, and $k_{e}$ $\left(\mathrm{m}^{2} \mathrm{~s}^{-1}\right)$ is the transfer coefficient for heat and water vapor within the canopy air space. Second, Eq. (2) cannot be used to simulate saturated flow in soils because the spatial gradients in $\Theta_{m}^{\text {soil }}$ are zero under saturated conditions. To address this issue, the hydrology state equation for the soil subdomain is modified to use the pressure-based form of Richards' equation (Miller et al. 1998) with matric head $\psi(\mathrm{m})$ as the state variable:

$$
S_{s} \frac{\Theta_{m}^{\text {soil }}}{\theta_{s}} \frac{\partial \psi_{0}}{\partial t}+\frac{d \Theta_{m}^{\text {soil }}}{d \psi_{0}} \frac{\partial \psi_{0}}{\partial t}=-\frac{\partial q_{\mathrm{liq}}^{\text {soil }}}{\partial z}+\mathcal{M}_{\mathrm{sink}}^{\mathrm{soil}},
$$

where $\psi_{0}$ is the matric potential that corresponds to the volumetric fraction of total water $\Theta_{m}^{\text {soil }}, S_{s}\left(\mathrm{~m}^{-1}\right)$ is the specific storage coefficient, and $\theta_{s}(-)$ is the saturated water content (i.e., the soil porosity). Equation (15) is an extension of Eq. (2), where the first term on the LHS accounts for the compressibility of the fluid and the aquifer. The first term on the LHS of Eq. (15) is necessary to simulate saturated flow. Equation (15) excludes the vertical flux of frozen water (e.g., snowfall), $\partial q_{\mathrm{ice}}^{\text {soil }} / \partial z$, because $q_{\mathrm{ice}}^{\text {soil }}$ only occurs in the vegetation and snow domains. Solving Eq. (15) requires the closure relationship

$$
\Theta_{m}^{\text {soil }}\left(\psi_{0}\right)=S_{*}\left(\psi_{0}\right),
$$

where $S_{*}(\cdot)$ is a soil-water-retention function, e.g., the van Genuchten (1980) function, which is used to calculate $d \Theta_{m}^{\text {soil }} / d \psi_{0}$ in Eq. (15). The state variable $\psi_{0}$ in Eq. (15) is used to generalize the hydrology state equation for the soil subdomain to simulate the storage and transmission of water in partially frozen soils: $\psi_{0}$ is the "unfrozen equivalent" matric potential, obtained from $\psi_{0}=\psi_{*}\left(\theta_{s}-\theta_{\text {air }}\right)$, where $\psi_{*}(\cdot)$ is the inverse of $S_{*}(\cdot)$.

\section{b. Model fluxes}

The vertical energy fluxes in Eq. (1) are defined for the vegetation domains as

$$
F^{\Omega}=\left\{\begin{array}{cl}
-C_{p}^{\mathrm{cas}} k_{e} \frac{\partial T^{\mathrm{cas}}}{\partial z}, & \Omega=\mathrm{cas}, \\
Q_{\mathrm{swd}}^{\mathrm{veg}}+Q_{\mathrm{lwd}}^{\mathrm{veg}}+Q_{\mathrm{swu}}^{\mathrm{veg}}+Q_{\mathrm{lwu}}^{\mathrm{veg}}+Q_{p}^{\mathrm{veg}}, & \Omega=\mathrm{veg} .
\end{array}\right.
$$

These fluxes for the snow and soil subdomains $(\Omega=\mathrm{ss}=$ snow, soil) are defined as

$$
F^{\mathrm{ss}}=\left\{\begin{array}{cc}
Q_{\mathrm{swd}}^{\mathrm{sfc}}+Q_{\mathrm{lwd}}^{\mathrm{sfc}}+Q_{\mathrm{swu}}^{\mathrm{scc}}+Q_{\mathrm{lwu}}^{\mathrm{scc}}+Q_{\mathrm{sen}}^{\mathrm{scc}}+Q_{\mathrm{lat}}^{\mathrm{sfc}}+Q_{p}^{\mathrm{sfc}}, & z=z_{\mathrm{sfc}}, \\
-\lambda \frac{\partial T^{\mathrm{ss}}}{\partial z}, & z>z_{\mathrm{sfc}},
\end{array}\right.
$$


where $z_{\text {sfc }}$ is the vertical position of the surface-atmosphere interface-when the land is snow free, $z_{\mathrm{sfc}}$ defines the top of the soil profile (i.e., $z_{\mathrm{sfc}}=0$ ); when the land is snow covered, $z_{\mathrm{sfc}}$ defines the top of the snowpack. The vertical coordinate $z$ is defined as positive downward, so the vertical positions $z>z_{\mathrm{sfc}}$ are below the surface-atmosphere interface.

In Eq. (17), $k_{e}\left(\mathrm{~m}^{2} \mathrm{~s}^{-1}\right)$ is the transfer coefficient for heat and water vapor within the canopy air space; in Eq. (18), $\lambda$ $\left(\mathrm{J} \mathrm{m}^{-1} \mathrm{~K}^{-1} \mathrm{~s}^{-1}\right)$ is the thermal conductivity within the snowsoil domain, and depends on the fraction of constituents at depth $z$. In Eqs. (17) and (18), $Q_{\text {swd }}\left(\mathrm{J} \mathrm{m}^{-2} \mathrm{~s}^{-1}\right)$ and $Q_{\text {lwd }}$ $\left(\mathrm{J} \mathrm{m}^{-2} \mathrm{~s}^{-1}\right)$ are the downwelling shortwave and longwave radiation fluxes, $Q_{\text {swu }}\left(\mathrm{J} \mathrm{m}^{-2} \mathrm{~s}^{-1}\right)$ and $Q_{\text {lwu }}\left(\mathrm{J} \mathrm{m}^{-2} \mathrm{~s}^{-1}\right)$ are the upwelling shortwave and longwave radiation fluxes, $Q_{p}\left(\mathrm{~J} \mathrm{~m}^{-2} \mathrm{~s}^{-1}\right)$ is the heat advected with precipitation, $Q_{\text {sen }}\left(\mathrm{J} \mathrm{m}^{-2} \mathrm{~s}^{-1}\right)$ and $Q_{\text {lat }}$ $\left(\mathrm{J} \mathrm{m}^{-2} \mathrm{~s}^{-1}\right)$ are the sensible and latent heat fluxes.

The energy source-sink flux terms in Eq. (1) are

$$
\mathcal{F}_{\text {sink }}^{\Omega}=\left\{\begin{array}{cl}
-\mathcal{F}_{\text {sen }}^{\mathrm{veg}}, & \Omega=\text { cas }, \\
\mathcal{F}_{\text {sen }}^{\mathrm{veg}}+\mathcal{F}_{\text {lat }}^{\mathrm{veg}}, & \Omega=\text { veg }, \\
0, & \Omega=\text { snow, soil },
\end{array}\right.
$$

where $\mathcal{F}_{\text {sen }}^{\mathrm{veg}}\left(\mathrm{J} \mathrm{m}^{-3} \mathrm{~s}^{-1}\right)$ and $\mathcal{F}_{\text {lat }}^{\mathrm{veg}}\left(\mathrm{J} \mathrm{m}^{-3} \mathrm{~s}^{-1}\right)$ are the volumetric sensible and latent heat fluxes, respectively, from the vegetation canopy to the canopy air space, and defined as positive toward the vegetation canopy. The sensible and latent heat fluxes are not part of the vertical fluxes in the vegetation subdomain, Eq. (17), because the source-sink flux term in Eq. (1), $\mathcal{F}_{\text {sink }}^{\Omega}$, includes the sensible and latent heat fluxes between the vegetation canopy and the canopy air space.

The hydrology source-sink flux terms in Eq. (2) are

$$
\mathcal{M}_{\text {sink }}^{\Omega}=\left\{\begin{array}{rlrl}
0, & & \Omega & =\text { cas }, \\
\mathcal{M}_{\text {sub }}+\mathcal{M}_{\text {evap }}, & & \Omega=\text { veg, snow }, \\
\mathcal{M}_{\text {sub }}+\mathcal{M}_{\text {evap }}+\mathcal{M}_{\text {trans }}+\mathcal{M}_{\text {lf }}, & & \Omega & =\text { soil },
\end{array}\right.
$$

where $\mathcal{M}_{\text {sub }}\left(\mathrm{s}^{-1}\right)$ defines the source-sink flux for frost/sublimation, $\mathcal{M}_{\text {evap }}\left(\mathrm{s}^{-1}\right)$ defines the source-sink flux for condensation/evaporation, $\mathcal{M}_{\text {trans }}\left(\mathrm{s}^{-1}\right)$ defines the transpiration losses, and $\mathcal{M}_{\mathrm{lf}}\left(\mathrm{s}^{-1}\right)$ is the net lateral flux of water. We note that no water is stored in the canopy air space, and hence $\mathcal{M}_{\text {sink }}^{\text {cas }}=0$.

\section{c. Spatial discretization}

The spatial discretization of land models is handled differently for the different model subdomains. For vegetation, the general model equations in section $2 \mathrm{a}$ can be discretized into a single canopy layer, i.e., the so-called "big-leaf" model (e.g., Dai et al. 2004), or multiple canopy layers (e.g., Bonan et al. 2018). For snow, the spatial (vertical) discretization is typically time varying. The snow subdomain is discretized into layers, and the depth of each snow layer is recomputed at the end of each time step. Snow layers are subdivided or combined when layer depths meet specific criteria; i.e., a snow layer is divided into two when its depth is larger than a prescribed threshold and combined with one of its neighbors when its depth is smaller than a prescribed threshold. For soil, the spatial discretization is typically time invariant. The soil subdomain can be discretized into any number of layers of variable thickness. Thinner soil layers are used near the top of the soil subdomain to better capture the effects of diurnal temperature forcing and large moisture gradients.

\section{1) THERMODYNAMICS}

The spatial discretization of the conservation equation for thermodynamics in the vegetation domain is obtained from Eqs. (1), (17), and (19). Using a single canopy layer, the volumetric sensible and latent heat fluxes in Eq. (19) can be defined as

$$
\begin{aligned}
& \mathcal{F}_{\text {sen }}^{\text {veg }}=\frac{Q_{\text {sen }}^{\text {veg }}}{D_{\text {can }}}, \\
& \mathcal{F}_{\text {lat }}^{\text {veg }}=\frac{Q_{\text {sub }}^{\text {veg }}+Q_{\text {evap }}^{\text {veg }}+Q_{\text {trans }}^{\text {veg }}}{D_{\text {can }}},
\end{aligned}
$$

where $Q_{\mathrm{sen}}^{\mathrm{veg}}\left(\mathrm{J} \mathrm{m}^{-2} \mathrm{~s}^{-1}\right)$ is the sensible heat flux from the vegetation canopy to the canopy air space, $Q_{\text {sub }}^{\text {veg }}\left(\mathrm{J} \mathrm{m}^{-2} \mathrm{~s}^{-1}\right), Q_{\text {evap }}^{\text {veg }}$ $\left(\mathrm{J} \mathrm{m}^{-2} \mathrm{~s}^{-1}\right)$, and $Q_{\text {trans }}^{\mathrm{veg}}\left(\mathrm{J} \mathrm{m}^{-2} \mathrm{~s}^{-1}\right)$ are respectively the heat fluxes associated with sublimation, evaporation, and transpiration, and $D_{\text {can }}=z_{\text {bot }}^{\mathrm{veg}}-z_{\text {top }}^{\mathrm{veg}}(\mathrm{m})$ is the depth of the vegetation canopy. The spatially discretized thermodynamic state equation for the vegetation canopy can then be given as

$$
\begin{aligned}
C_{p}^{\mathrm{veg}} \frac{d T^{\mathrm{veg}}}{d t}-L_{\mathrm{fus}} \rho_{\mathrm{ice}} \frac{d \theta_{\text {ice }}^{\mathrm{veg}}}{d t}= & \frac{Q_{\mathrm{sw}, \text { net }}^{\mathrm{veg}}+Q_{\mathrm{lw}, \text { net }}^{\mathrm{veg}}}{D_{\text {can }}}+\frac{Q_{\mathrm{sen}}^{\mathrm{veg}}}{D_{\text {can }}} \\
& +\frac{Q_{\mathrm{sub}}^{\mathrm{veg}}+Q_{\mathrm{evap}}^{\mathrm{veg}}+Q_{\text {trans }}^{\mathrm{veg}}}{D_{\text {can }}}+\frac{Q_{p}^{\mathrm{veg}}}{D_{\text {can }}},
\end{aligned}
$$

where $Q_{\mathrm{sw}, \text { net }}^{\mathrm{veg}}$ and $Q_{\mathrm{lw} \text {,net }}^{\mathrm{veg}}$ are the net shortwave and longwave fluxes absorbed by the vegetation canopy. The first term on the RHS of Eq. (23) is the net radiation balance for the vegetation canopy, the second term is the sensible heat flux from the vegetation canopy to the canopy air space, the third term is the latent heat flux from the vegetation canopy to the canopy air space, and the fourth term is the heat advected with precipitation.

The spatial discretization in the canopy air space can be obtained similarly. With one vegetation layer, it is only necessary to compute the vertical fluxes at the bottom and top of the canopy air space subdomain. The latent heat fluxes in the canopy air space are defined in Eq. (14); i.e., $Q_{\text {lat }}^{\text {cas }}(z)=-\rho_{\text {air }} k_{e} \partial \vartheta^{\text {cas }} / \partial z$. Given Eq. (14), the latent heat fluxes can be defined as

$$
\begin{aligned}
Q_{\mathrm{lat}}^{\mathrm{sfc}} & =-\rho_{\mathrm{air}} k_{e} \frac{\vartheta^{\mathrm{sfc}}-\vartheta^{\mathrm{cas}}}{z_{\mathrm{sfc}}-z_{\mathrm{cas}}}, \\
Q_{\mathrm{lat}}^{\mathrm{total}} & =-\rho_{\mathrm{air}} k_{e} \frac{\vartheta^{\mathrm{cas}}-\vartheta^{\mathrm{atm}}}{z_{\mathrm{cas}}-z_{\mathrm{atm}}},
\end{aligned}
$$

where $Q_{\text {lat }}^{\text {sfc }}\left(\mathrm{J} \mathrm{m}^{-2} \mathrm{~s}^{-1}\right)$ and $Q_{\text {lat }}^{\text {total }}\left(\mathrm{J} \mathrm{m}^{-2} \mathrm{~s}^{-1}\right)$ define the latent heat flux at the bottom and the top of the canopy air space. The sensible heat flux within the canopy air space is defined in Eq. (17); i.e., $Q_{\mathrm{sen}}^{\text {cas }}(z)=-C_{p}^{\text {cas }} k_{e} \partial T^{\text {cas }} / \partial z$. Given Eq. (17), the 
sensible heat fluxes at the boundaries of the canopy air space subdomain are computed from the gradients in temperature from the surface to the canopy air space and from the canopy air space to the upper boundary:

$$
\begin{aligned}
Q_{\mathrm{sen}}^{\mathrm{sfc}} & =-C_{p}^{\mathrm{cas}} k_{e} \frac{T^{\mathrm{sfc}}-T^{\mathrm{cas}}}{z_{\mathrm{sfc}}-z_{\mathrm{cas}}}, \\
Q_{\mathrm{sen}}^{\mathrm{total}} & =-C_{p}^{\mathrm{cas}} k_{e} \frac{T^{\mathrm{cas}}-T^{\mathrm{atm}}}{z_{\mathrm{cas}}-z_{\mathrm{atm}}},
\end{aligned}
$$

where $Q_{\mathrm{sen}}^{\mathrm{sfc}}\left(\mathrm{J} \mathrm{m}^{-2} \mathrm{~s}^{-1}\right)$ and $Q_{\mathrm{sen}}^{\text {total }}\left(\mathrm{J} \mathrm{m}^{-2} \mathrm{~s}^{-1}\right)$ define the sensible heat flux at the bottom and the top of the canopy air space.

The conservation equations for temperature and water vapor in the canopy air space are treated differently. The spatially discretized conservation equation for temperature in the canopy air space is formulated directly in order to simplify the stability corrections. The conservation equation for temperature in the canopy air space is

$$
C_{p}^{\mathrm{cas}} \frac{d T^{\mathrm{cas}}}{d t}=-\frac{Q_{\mathrm{sen}}^{\mathrm{scc}}-Q_{\mathrm{sen}}^{\mathrm{total}}}{D_{\mathrm{can}}}-\frac{Q_{\mathrm{sen}}^{\mathrm{veg}}}{D_{\mathrm{can}}} .
$$

We note that no water is stored in the canopy air space; hence, $\theta_{\text {ice }}^{\text {cas }} \equiv 0$, and the phase change term in Eq. (3) is neglected. We do not formulate a conservation equation for water vapor in the canopy air space. Instead, we make the simplification that

$$
Q_{\mathrm{lat}}^{\mathrm{total}}=Q_{\mathrm{evap}}^{\mathrm{veg}}+Q_{\mathrm{trans}}^{\mathrm{veg}}+Q_{\mathrm{lat}}^{\mathrm{sfc}}
$$

In this formulation, $\vartheta^{\text {cas }}$ in Eqs. (14), (24), and (25) is a diagnostic variable.

The snow and soil subdomains are discretized into multiple layers. Suppose that $\Delta z_{j}$ is the depth of layer $j$ in the snow or soil subdomain; the spatial discretization of the conservation equation for thermodynamics can then be written for layer $j$ as

$$
C_{p}^{\mathrm{ss}} \frac{d T_{j}^{\mathrm{ss}}}{d t}-L_{\text {fus }} \rho_{\mathrm{ice}} \frac{d \theta_{\mathrm{ice}_{j}}^{\mathrm{ss}}}{d t}=-\frac{F_{j+1 / 2}^{\mathrm{ss}}-F_{j-1 / 2}^{\mathrm{ss}}}{\Delta z_{j}}, \quad j=1,2, \ldots, J^{\mathrm{ss}}
$$

where the vertical energy fluxes are as defined in Eq. (18).

\section{2) Hydrology}

The spatial discretization of the conservation equation for the vegetation canopy hydrology can be obtained from Eqs. (2) and (20). The net solid and liquid precipitation fluxes are

$$
\begin{aligned}
& q_{\mathrm{ice}, \text { net }}^{\mathrm{veg}}=\left(q_{\mathrm{tf}, \text { snow }}^{\mathrm{veg}}+q_{\mathrm{unload}}^{\mathrm{veg}}\right)-q_{\mathrm{sf}}, \\
& q_{\mathrm{liq}, \text { net }}^{\mathrm{veg}}=\left(q_{\mathrm{tf}, \text { rain }}^{\mathrm{veg}}+q_{\mathrm{drip}}^{\mathrm{veg}}\right)-q_{\mathrm{rf}},
\end{aligned}
$$

where the first and second terms on the RHS define the fluxes at the bottom and top of the vegetation canopy, respectively. Here, $q_{\mathrm{sf}}\left(\mathrm{m} \mathrm{s}^{-1}\right)$ and $q_{\mathrm{rf}}\left(\mathrm{m} \mathrm{s}^{-1}\right)$ are respectively snowfall and rainfall, $q_{\mathrm{tf} \text {,snow }}^{\text {veg }}\left(\mathrm{m} \mathrm{s}^{-1}\right)$ and $q_{\mathrm{tf} \text {,rain }}^{\mathrm{veg}}\left(\mathrm{m} \mathrm{s}^{-1}\right)$ are the throughfall of snow and rain, $q_{\text {unload }}^{\mathrm{veg}}\left(\mathrm{m} \mathrm{s}^{-1}\right)$ is the unloading of snow from the vegetation canopy, and $q_{\text {drip }}^{\text {veg }}\left(\mathrm{m} \mathrm{s}^{-1}\right)$ is the drip of liquid water from the vegetation canopy. The loss of water from evaporation and sublimation, i.e., contributing to the source-sink flux terms $S_{\text {evap }}$ and $S_{\text {sub }}$ in Eq. (20), are related to the energy used for evaporation and sublimation, i.e.,

$$
\begin{aligned}
\mathcal{M}_{\text {sub }}^{\text {veg }} & =\frac{Q_{\text {sub }}^{\text {veg }}}{L_{\text {sub }} \rho_{\text {liq }} D_{\text {can }}}, \\
\mathcal{M}_{\text {evap }}^{\text {veg }} & =\frac{Q_{\text {evap }}^{\text {veg }}}{L_{\text {vap }} \rho_{\text {liq }} D_{\text {can }}},
\end{aligned}
$$

where $L_{\text {vap }}\left(\mathrm{J} \mathrm{kg}^{-1}\right)$ and $L_{\text {sub }}\left(\mathrm{J} \mathrm{kg}^{-1}\right)$ are respectively the latent heat of evaporation and sublimation. The spatially discretized conservation equation for the vegetation canopy hydrology is then

$$
\frac{d \Theta_{m}^{\mathrm{veg}}}{d t}=-\frac{q_{\mathrm{ice}, \text { net }}^{\mathrm{veg}}}{D_{\text {can }}}-\frac{q_{\mathrm{liq}, \text { net }}^{\mathrm{veg}}}{D_{\text {can }}}+\mathcal{M}_{\mathrm{sub}}^{\mathrm{veg}}+\mathcal{M}_{\mathrm{evap}}^{\mathrm{veg}},
$$

where all other terms are as defined previously.

The spatial discretization of the conservation equations for snow and soil hydrology is obtained in an analogous manner to vegetation. The net vertical flux of solid water is

$$
q_{\text {ice,net }_{j}}^{\text {ss }}=\left\{\begin{array}{cc}
-\left(q_{\mathrm{tf}, \text { snow }}^{\mathrm{veg}}+q_{\text {unload }}^{\mathrm{veg}}\right), & j=1, \\
0, & j>1,
\end{array}\right.
$$

where $j=1$ defines the top layer in the snow +soil domain. We note that if there is no vegetation or if vegetation is buried, then $q_{\mathrm{tf} \text {,snow }}^{\mathrm{veg}}=q_{\mathrm{sf}}$ and $q_{\mathrm{unload}}^{\mathrm{veg}}=0$. Similarly, the sublimation and evaporation fluxes are apportioned to the uppermost layer in the snow + soil domain

$$
\mathcal{M}_{\mathrm{sub}_{j}}^{\mathrm{ss}}+\mathcal{M}_{\mathrm{evap}_{j}}^{\mathrm{ss}}=\left\{\begin{array}{cc}
\frac{Q_{\mathrm{sub}}^{\mathrm{scc}}}{L_{\mathrm{sub}} \rho_{\mathrm{liq}} \Delta z_{j}^{\Omega}}+\frac{Q_{\mathrm{evap}}^{\mathrm{sc}}}{L_{\mathrm{vap}_{\mathrm{liq}} \rho_{\mathrm{liq}} \Delta z_{j}^{\Omega}}}, & j=1, \\
0, & j>1 .
\end{array}\right.
$$

The transpiration fluxes are apportioned to the soil layers via

$$
\mathcal{M}_{\text {trans }_{j}}^{\text {ss }}=\left\{\begin{array}{cl}
0, & \Omega=\text { snow }, \\
f_{j} \frac{Q_{\text {trans }}^{\text {sfc }}}{L_{\text {vap }} \rho_{\text {liq }} \Delta z_{j}^{\text {soil }}}, & \Omega=\text { soil },
\end{array}\right.
$$

where $f_{j}$ is the fraction of the transpiration flux apportioned to layer $j$ and depends on soil water content and root density.

The spatially discretized conservation equation for soil and snow hydrology is then

$$
\begin{aligned}
\frac{d \Theta_{m_{j}}^{\text {snow }}}{d t}= & -\frac{q_{\mathrm{ice}_{\text {net }}}^{\text {snow }}}{\Delta z_{j}}-\frac{q_{\mathrm{liq}_{j+1 / 2}}^{\text {snow }}-q_{\mathrm{liq}_{j-1 / 2}}^{\text {snow }}}{\Delta z_{j}} \\
& +\mathcal{M}_{\text {sink }_{j}}^{\text {snow }}, \quad j=1,2, \ldots, J^{\text {snow }},
\end{aligned}
$$

where $\mathcal{M}_{\text {sink }_{j}}^{\text {snow }}=\mathcal{M}_{\text {sub }_{j}}^{\text {snow }}+\mathcal{M}_{\text {evap }_{j}}^{\text {snow }}$ and

$$
\begin{aligned}
S_{s} \frac{\Theta_{m_{j}}^{\text {soil }}}{\theta_{s_{j}}} \frac{d \psi_{0_{j}}}{d t}+\frac{d \Theta_{m_{j}}^{\text {soil }}}{d \psi_{0_{j}}} \frac{d \psi_{0_{j}}}{d t}= & -\frac{q_{\mathrm{liq}_{j+1 / 2}}^{\text {soil }}-q_{\mathrm{liq}_{j-1 / 2}}^{\text {soil }}}{\Delta z_{j}} \\
& +\mathcal{M}_{\text {sink }_{j}}^{\text {soil }}, j=1,2, \ldots, J^{\text {soil }},
\end{aligned}
$$


where

$$
\mathcal{M}_{\text {sink }_{j}}^{\text {soil }}=\mathcal{M}_{\mathrm{sub}_{j}}^{\text {soil }}+\mathcal{M}_{\mathrm{evap}_{j}}^{\text {soil }}+\mathcal{M}_{\text {trans }_{j}}^{\text {soil }}+\mathcal{M}_{\mathrm{lf}_{j}}^{\text {soil }}
$$

with $\mathcal{M}_{\mathrm{lf}_{j}}^{\text {soil }}$ the source-sink flux term for lateral flow.

\section{d. Temporal discretization}

The temporal discretization of the state equations requires special attention in order to conserve energy and mass. The following subsections describe methods for conservative temporal approximations of Eqs. (1) and (2). To show application in existing land models, appendix A provides details on the temporal discretization and solution of the model equations using the first-order implicit Euler method.

\section{1) THERMODYNAMics}

We write a conservative discretization of the enthalpy form of the heat equation, Eq. (1), as

$$
\frac{\Delta H_{j, n+1}^{\Omega}}{\Delta t_{n}}=\frac{F_{\text {net }_{j}}^{\Omega}}{\Delta z_{j}^{\Omega}}
$$

where $\Delta H_{j, n+1}^{\Omega}=\left[H_{j}^{\Omega}\left(t_{n+1}\right)-H_{j}^{\Omega}\left(t_{n}\right)\right]$ is the change in enthalpy $\left(\mathrm{J} \mathrm{m}^{-3}\right)$ over the time interval $\left[t_{n}, t_{n+1}\right]$, with $t_{n+1}=t_{n}+\Delta t_{n}$, and $\Delta z_{j}^{\Omega}=D_{\text {can }}=z_{\text {bot }}-z_{\text {top }}$ for $\Omega=$ cas, veg and $\Delta z_{j}^{\Omega}=z_{j+1 / 2}-z_{j-1 / 2}$ for $\Omega=$ snow, soil. Making use of Eqs. (23), (28), and (30),

$$
F_{\mathrm{net}_{j}}^{\Omega}= \begin{cases}-\left(Q_{\mathrm{sen}}^{\mathrm{scc}}-Q_{\mathrm{sen}}^{\mathrm{total}}\right)-\left(Q_{\mathrm{sen}}^{\mathrm{veg}}\right), & \Omega=\mathrm{cas}, \\ \left(Q_{\mathrm{sw}, \text { net }}^{\mathrm{ve}}+Q_{\mathrm{lw}, \mathrm{net}}^{\mathrm{veg}}\right)+\left(Q_{\mathrm{sen}}^{\mathrm{veg}}\right)+\left(Q_{\mathrm{sub}}^{\mathrm{veg}}+Q_{\mathrm{evap}}^{\mathrm{veg}}+Q_{\mathrm{trans}}^{\mathrm{veg}}\right)+\left(Q_{p}^{\mathrm{veg}}\right), & \Omega=\mathrm{veg}, \\ -\left(F_{j+1 / 2}^{\mathrm{ss}}-F_{j-1 / 2}^{\mathrm{ss}}\right), & \Omega=\text { snow, soil }\end{cases}
$$

Although it is valid to discretize the enthalpy form of the heat equation, Eq. (1), we are interested in the temperature form of the heat equation, Eqs. (10) and (12), because the net fluxes $F_{\text {net }_{j}}^{\Omega}$ are parameterized as a function of temperature. Formulating the heat equation in terms of temperature is also useful in order to directly control the numerical error of the temperature state variables. The temperature form of the heat equation in Eq. (12) can be discretized as

$$
\tilde{C}_{a_{j}}^{\Omega} \frac{\Delta T_{j, n+1}^{\Omega}}{\Delta t_{n}}=\frac{F_{\mathrm{net}_{j}}^{\Omega}}{\Delta z_{j}^{\Omega}},
$$

where $\tilde{C}_{a}\left(\mathrm{~J} \mathrm{~m}^{-3} \mathrm{~K}^{-1}\right)$ is the apparent heat capacity and $\Delta T_{j, n+1}^{\Omega}=\left[T_{j}^{\Omega}\left(t_{n+1}\right)-T_{j}^{\Omega}\left(t_{n}\right)\right]$ is the change in temperature (K) over the time interval $\left[t_{n}, t_{n+1}\right]$.

Comparing Eqs. (41) and (43), it is apparent that Eq. (43) conserves energy if $\tilde{C}_{a_{j}}^{\Omega} \Delta T_{j, n+1}^{\Omega}=\Delta H_{j, n+1}^{\Omega}$ (e.g., see Tubini et al. 2020). Indeed, estimates of $C_{a}$ at an arbitrary point in the time step (e.g., $t_{n}$ or $t_{n+1}$ ) do not typically conserve energy. A conservative method for Eq. (43) can be obtained using

$$
\tilde{C}_{a_{j}}^{\Omega}=\frac{\Delta H_{j, n+1}^{\Omega}}{\Delta T_{j, n+1}^{\Omega}} .
$$

We can interpret $\tilde{C}_{a}$ as the value of the apparent heat capacity that is necessary to conserve energy. Because the approximation in Eq. (44) only requires modifying the estimate $\tilde{C}_{a}$, this approach can easily be implemented in existing land models.

Separating out the temperature and phase change terms on the LHS of Eq. (43), i.e., as in Eqs. (10), (23), (28), and (30), and making use of Eq. (44), in the limit as $\Delta t \rightarrow 0$, we have

$$
\frac{\Delta H_{T_{j}}^{\Omega}}{\Delta T_{j}^{\Omega}} \frac{d T_{j}^{\Omega}}{d t}-L_{\text {fus }} \rho_{\text {ice }} \frac{\Delta \theta_{\text {ice }_{j}}^{\Omega}}{\Delta t_{n}}=\frac{F_{\text {net }_{j}}^{\Omega}}{\Delta z_{j}^{\Omega}}, \quad j=1,2, \ldots, J^{\Omega},
$$

where $J^{\Omega}$ is the number of layers in subdomain $\Omega$. In Eq. (45), the enthalpy $H_{T}^{\Omega}$ and volumetric ice content $\theta_{\text {ice }}^{\Omega}$ are both diagnostic variables. The methods used to calculate enthalpy are detailed in appendix B. The quantity $\theta_{\text {ice }}^{\text {snow }}\left(T^{\text {snow }}, \Theta_{m}^{\text {snow }}\right)$ is calculated using Eqs. (7) and $(62) ; \theta_{\text {ice }}^{\text {soil }}\left(T^{\text {soil }}, \psi_{0}\right)$ is calculated using Eqs. (67)-(73).

\section{2) SOIL HYDROLOGY}

Care is also needed to conserve mass in soil. The discretized form of Eq. (15) can be written as

$$
S_{s} \frac{\Theta_{m_{j}}^{\text {soil }}}{\theta_{s_{j}}} \frac{\Delta \psi_{0_{j, n+1}}}{\Delta t}+\tilde{C}_{\psi_{j}} \frac{\Delta \psi_{0_{j, n+1}}}{\Delta t}=\frac{q_{\text {net }_{j}}^{\text {soil }}}{\Delta z_{j}^{\text {soil }}}+\mathcal{M}_{\text {sink }_{j}}^{\text {soil }}, \quad j=1,2, \ldots, J^{\text {soil }},
$$

with

$$
q_{\mathrm{net}_{j}}^{\text {soil }}=-\left[\left(q_{\text {liq }}^{\text {soil }}\right)_{j+1 / 2}-\left(q_{\text {liq }}^{\text {soil }}\right)_{j-1 / 2}\right] .
$$

In Eq. (46), $\Delta \psi_{0_{j, n+1}}=\left[\psi_{0_{j}}\left(t_{n+1}\right)-\psi_{0_{j}}\left(t_{n}\right)\right]$ and $\Delta \Theta_{m_{j, n+1}}^{\text {soil }}=\left[\Theta_{m_{j}}^{\text {soil }}\right.$ $\left.\left(t_{n+1}\right)-\Theta_{m_{j}}^{\text {soil }}\left(t_{n}\right)\right]$ are respectively the change in matric head (m) and total volumetric water content (-) over the time interval $\left[t_{n}, t_{n+1}\right]$, and $\tilde{C}_{\psi_{j}}^{\text {soil }}=d \Theta_{m_{j}}^{\text {soil }} / d \psi_{0_{j}}\left(\mathrm{~m}^{-1}\right)$ is the slope of the water retention curve. Similar to Eq. (43), conservation of mass can be satisfied using

$$
\tilde{C}_{\psi_{j}}^{\text {soil }}=\frac{\Delta \Theta_{m_{j}, n+1}^{\text {soil }}}{\Delta \psi_{0_{j}, n+1}}
$$

which corresponds to the standard chord slope approximation examined by Rathfelder and Abriola (1994). Further discussions of mass conservation issues are in Milly (1984) and Celia et al. (1990).

Given Eqs. (15) and (48), in the limit as $\Delta t \rightarrow 0$, we have 


$$
S_{s} \frac{\Theta_{m_{j}}^{\text {soil }}}{\theta_{s_{j}}} \frac{d \psi_{0_{j}}}{d t}+\frac{\Delta \Theta_{m_{j}}^{\text {soil }}}{\Delta \psi_{0_{j}}} \frac{d \psi_{0_{j}}}{d t}=\frac{q_{\text {net }_{j}}^{\text {soil }}}{\Delta z_{j}^{\text {soil }}}+\mathcal{M}_{\text {sink }_{j}}^{\text {soil }}, \quad j=1,2, \ldots, J^{\text {soil }} .
$$

In Eq. (49), $\Theta_{m}^{\text {soil }}$ is a diagnostic variable computed from $\psi_{0}$.

\section{e. Numerical solutions}

Up to this point, the model development has been largely general. Most existing land models are some variant of Eqs. (1) and (2). Although land models apply to 3D space $(x, y, z)$, as is common, we formulate the conservation laws for fixed $x$ and $y$ and solve each $1 \mathrm{D}$ column in the vertical dimension $z$ independently. The lateral flux across soil columns is handled as a source-sink flux term in the $1 \mathrm{D}$ equations. The differences among land models depend on aspects such as what physical processes are included, how the fluxes are parameterized, and how the model domain is discretized.

In this study, we solve this system of equations using IDA, which is part of the Suite of Nonlinear and Differential/Algebraic Equation Solvers (SUNDIALS) suite (Hindmarsh et al. 2005), as implemented in the Structure for Unifying Multiple Modeling Alternatives (SUMMA) model (Clark et al. 2015b). IDA is a package for the solution of implicit ordinary differential equation (ODE) and differential-algebraic equation (DAE) systems in the general form $\mathbf{f}\left(t, \mathbf{y}, \mathbf{y}^{\prime}\right)=0$. The integration method in IDA uses variable-length time steps and methods from the backward differentiation formula (BDF) family of orders 1-5. IDA is written in C, but for use with FORTRAN applications like SUMMA, a set of FORTRAN/C interface routines, called FIDA, is also supplied in the SUNDIALS suite.

The simulations take place over a time interval described in terms of a sequence of "data windows" (i.e., data time steps) over which certain inputs or other quantities are fixed and then updated from one window to the next. Fluxes such as precipitation and shortwave radiation are often taken to be averages over a data window, e.g., downwelling shortwave radiation changes during daylight hours and can change rapidly during otherwise innocuous events such as the sun going behind a cloud; similarly, precipitation can start and stop abruptly. Because of the potential discontinuities arising in the terms of the differential equations, the integration in SUMMA/SUNDIALS is restarted on each data window.

\section{Synthetic test cases}

Synthetic test cases-the laugh tests-are used to evaluate the implementation of the model equations, including impacts of the numerical approximations. As discussed by Clark et al. (2015a), synthetic test problems have been used to evaluate the numerical implementation of Richards' equation (Celia et al. 1990; Boone and Wetzel 1996; Tocci et al. 1997; Lee and Abriola 1999; Vanderborght et al. 2005; Miller et al. 2006), model simulations of cryosuction processes during soil freezing (Hansson et al. 2004; Painter 2011; Noh et al. 2012; Kurylyk et al. 2014; Grenier et al. 2018), model simulations of water movement through snow during rain-on-snow events (Colbeck 1976; Clark et al. 2017), model simulations of lateral subsurface flow (Wigmosta and Lettenmaier 1999; Rupp and Selker 2005, 2006; Bogaart et al. 2013), and overland flow (Parlange et al. 1981; Govindaraju et al. 1990; Mizumura 2006; Mizumura and Ito 2011a,b). Synthetic experiments are also used to simulate interlinked physical processes. For example, Maxwell et al. (2014) examined cases of runoff and return flow on an inclined hillslope, runoff over a tilted $\mathrm{V}$-shaped catchment, and runoff generation on a heterogeneous 1D slab.

Synthetic test cases are important because they provide evidence that the land model equations are formulated and implemented correctly. We consider synthetic test cases as "laugh tests" for land models-if a land model fails a laugh test, then it is difficult to seriously consider the use of the land model for general applications. Synthetic test cases provide the most rudimentary test of model capabilities, yet they are not widely reported in land model evaluation efforts. Such test cases are important not just in the initial stage of model development; the tests are also important as part of continuous model testing to check that new modeling enhancements do not introduce unintended errors.

The laugh tests are designed to test the numerical solution of the coupled energy and mass equations in different model subdomains. To the extent possible, the test cases are designed to analyze model behavior across different model subdomains (e.g., the soil subdomain, the snow subdomain) and directly evaluate the coupling processes (e.g., the coupling between vertical processes and lateral flow, the coupling between thermodynamic and hydrological processes). The test cases are hence less focused on the parameterization of individual processes; instead, the test cases focus on how individual processes combine to affect the temporal evolution of model state variables for different model subdomains. Critically, the laugh tests do not evaluate whether the land model equations are appropriate; the laugh tests simply check that the model equations are implemented correctly and are able to reproduce known results.

Although the laugh tests introduced here are by no means comprehensive, they do provide a useful starting point to assess the numerical implementation of land models. The laugh tests include three test cases for storage and transmission of water in soils (section 3a), one test case for lateral subsurface flow (section 3b), one test case for coupled hydrological and thermodynamic processes in snow (section 3c), and one test case for cryosuction processes in soil (section 3d). All of the laugh tests are solved using the same model (SUMMA) using different model parameters and different boundary conditions. To ensure that the spatial discretization does not dominate the overall error compared to the time stepping, we impose fine vertical discretizations for all test cases. The laugh tests use an accuracy tolerance of $1 \times 10^{-6}$ for all model state variables.

\section{a. Storage and transmission of water in soils}

Richards' equation is a common approach used in land models to simulate the storage and transmission of water in 
TABLE 2. Parameters for the test cases of Celia et al. (1990) and Miller et al. (1998).

\begin{tabular}{lcccc}
\hline \hline & \multicolumn{2}{c}{ Celia et al. } & \multicolumn{2}{c}{ Miller et al. } \\
\cline { 2 - 5 } Soil type & "New Mexico" & Sand & Loam & Clay loam \\
\hline$\theta_{r}(-)$ & 0.102 & 0.093 & 0.078 & 0.095 \\
$\theta_{s}(-)$ & 0.368 & 0.301 & 0.430 & 0.410 \\
$\alpha\left(\mathrm{m}^{-1}\right)$ & 3.350 & 5.470 & 3.600 & 1.900 \\
$n(-)$ & 2.000 & 4.264 & 1.560 & 1.310 \\
$m(-)$ & $1-(1 / n)$ & $1-(1 / n)$ & $7.17 \times 10^{-7}$ \\
$k_{s}\left(\mathrm{~m} \mathrm{~s}^{-1}\right)$ & $9.22 \times 10^{-5}$ & $5.83 \times 10^{-5}$ & $2.80 \times 10^{-6}$ & $10^{-6}$ \\
$S_{s}\left(\mathrm{~m}^{-1}\right)$ & $10^{-6}$ & $10^{-6}$ & $10^{-6}$ & 0 \\
$S_{\text {sink }}^{\text {soil }}\left(\mathrm{s}^{-1}\right)$ & 0 & 0 & 0 & 2 \\
$z_{\text {max }}(\mathrm{m})$ & 0.6 & 10 & 5 & 2 \\
\hline
\end{tabular}

soils (Clark et al. 2015a). As discussed earlier and defined in Eq. (15), variably saturated flow problems require formulating Richards' equation with matric head $\psi(\mathrm{m})$ as the state variable, i.e., the pressure-based form of Richards' equation. In this formulation, $\theta_{\text {liq }}^{\text {soil }}$ is a diagnostic variable computed from $\psi$ using the soil-water-retention function defined in Eq. (16). The conservation equation for soil hydrology, Eq. (15), can then be written for unfrozen conditions as

$$
S_{s} \frac{\theta_{\mathrm{liq}}^{\text {soil }}}{\theta_{s}} \frac{\partial \psi}{\partial t}+\frac{d \theta_{\mathrm{liq}}^{\text {soil }}}{d \psi} \frac{\partial \psi}{\partial t}=-\frac{\partial q_{\mathrm{liq}}^{\text {sil }}}{\partial z}+\mathcal{M}_{\mathrm{sink}}^{\text {soil }},
$$

with

$$
q_{\mathrm{liq}}^{\mathrm{soil}}(\psi)=-k(\psi) \frac{\partial \psi}{\partial z}+k(\psi),
$$

where $k(\psi)$ is the hydraulic conductivity $\left(\mathrm{m} \mathrm{s}^{-1}\right)$. We note that Eq. (50) is formulated for unfrozen conditions, so $\Theta_{m}^{\text {soil }}=\theta_{\text {liq }}^{\text {soil }}$ and $\psi_{0}=\psi$.

The test cases examined here evaluate infiltration into initially dry soil, as formulated by Celia et al. (1990) and Miller et al. (1998). These test cases use the closure relations from van Genuchten (1980),

$$
\begin{aligned}
\theta_{\mathrm{liq}}^{\text {soil }}(\psi) & =\left\{\begin{array}{cc}
\frac{\theta_{s}-\theta_{r}}{\left[1+(-\alpha \psi)^{n}\right]^{m}}+\theta_{r}, & \psi \leq 0, \\
\theta_{s}, & \psi>0,
\end{array}\right. \\
k(\psi) & =\left\{\begin{array}{cc}
k_{s} \frac{\left\{1-(-\alpha \psi)^{n-1}\left[1+(-\alpha \psi)^{n}\right]^{-m}\right\}^{2}}{\left[1+(-\alpha \psi)^{n}\right]^{m / 2}}, & \psi \leq 0, \\
k_{s}, & \psi>0,
\end{array}\right.
\end{aligned}
$$

where $\theta_{r}$ is the residual water content $(-), \alpha$ is the capillary length scale $\left(\mathrm{m}^{-1}\right)$, the parameters $m(-)$ and $n(-)$ are related to the pore size distribution [typically $m=1-(1 / n)$ ], and $k_{s}$ is the saturated hydraulic conductivity $\left(\mathrm{m} \mathrm{s}^{-1}\right)$. The parameters for the test cases of Celia et al. and Miller et al. are fully specified in Table 2 .

The test case formulated by Celia et al. (1990) considers the propagation of a sharp infiltration front in a $0.6-\mathrm{m}$ soil column. For this test case, we solve Eqs. (50)-(53) subject to the following initial and boundary conditions

$$
\begin{aligned}
\psi(z, 0) & =\left\{\begin{array}{cc}
-0.75-\frac{9.25}{0.006} z, & 0 \leq z \leq 0.006, \\
-10, & z>0.006,
\end{array}\right. \\
\psi(0, t) & =-0.75, \\
\psi(0.6, t) & =-10 .
\end{aligned}
$$

The soil domain is discretized into 100 uniform layers, and the simulation time consists of 120 data windows of length $1800 \mathrm{~s}$ for a total simulation time of $60 \mathrm{~h}$.

Although the test case of Celia et al. has strong spatial and temporal gradients in pressure, its boundary conditions restrict simulations to unsaturated flow. Figure 2 illustrates the vertical profiles of pressure at various times throughout the simulation. The simulations shown in Fig. 2 closely match the independent numerical solutions shown in Celia et al. (1990) and Kavetski et al. (2001), building confidence in the numerical solutions.

The test cases formulated by Miller et al. (1998) evaluate infiltration into an initially hydrostatic soil profile, with a fixed water table at the lower boundary, subject to ponding at the surface. The test cases of Miller et al. hence evaluate model simulations of variably saturated flow. For these cases, we solve Eqs. (50)-(53) subject to the following initial and boundary conditions:

$$
\begin{aligned}
\psi(z, 0) & =z-z_{\max }, \\
\psi(0, t) & =0.1, \\
\psi\left(z_{\max }, t\right) & =0 .
\end{aligned}
$$

The domains are discretized into 800, 400, and 320 uniform layers for sand, loam, and clay, respectively, and the simulation time in each case consists of 240 data windows of length $900 \mathrm{~s}$ for a total simulation time of $60 \mathrm{~h}$.

Figure 3 illustrates the vertical profiles of pressure for the three soil types considered by Miller et al. (1998). The simulations in Fig. 3 have more numerical diffusion than the simulations in Miller et al. (1998). As with the test case from Celia et al. (1990), the test cases from Miller et al. (1998) present a didactic set of problems because of the sharp vertical gradients at the toe of the infiltration front.

The next test case was defined by Vanderborght et al. (2005) to evaluate the steady-state flux in layered soil profiles. This test case is useful because an analytical solution can be derived 


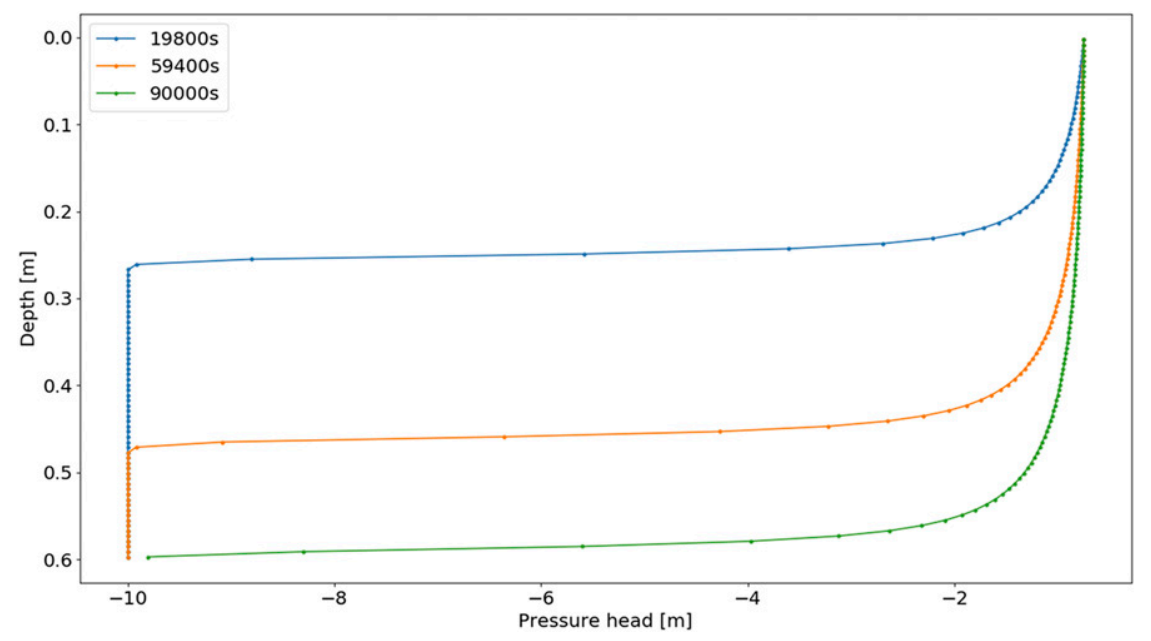

FIG. 2. Solution of the test problem from Celia et al. (1990), showing pressure profiles at various times during the model simulation.

to yield depth as a function of pressure head (Vanderborght et al. 2005),

$$
\Delta z=z_{1}-z_{2}=\int_{\psi\left(z_{2}\right)}^{\psi\left(z_{1}\right)}\left[\frac{q_{\mathrm{liq}}^{\text {soil }}(0, t)}{k(\psi)}-1\right]^{-1} d \psi
$$

The Vanderborght case is defined as one soil type for depth 0 $0.5 \mathrm{~m}$ overlying another soil type for depth $0.5-2 \mathrm{~m}$ for loam over sand, sand over loam, and clay over sand. The soil parameters are defined in Table 3. We solve Eqs. (50)-(53) subject to the initial and boundary conditions

$$
\begin{aligned}
\psi(z, 0) & =-20, \\
q_{\mathrm{liq}}^{\text {soil }}(0, t) & =5.79 \times 10^{-8}, \\
\frac{\partial \psi}{\partial z}(2, t) & =0 .
\end{aligned}
$$

In each case, the domain is discretized into 200 uniform layers, and the simulation time consists of data windows of length $3600 \mathrm{~s}$ for a total simulation time of $24000 \mathrm{~h}$. We note that the Vanderborght test cases are for steady-state conditions, so the simulation time is more than is required to bring the model to steady state.

Figure 4 illustrates the vertical profiles of pressure for the layered soil profiles studied by Vanderborght et al. (2005). Similar to the results presented by Vanderborght et al. (2005), the simulations in Fig. 4 provide close approximations to the analytical solutions.

\section{b. Lateral subsurface flow}

Lateral subsurface flow is a dominant hydrological process that has received limited attention in land models (Clark et al. 2015a; Fan et al. 2019). Recent approaches represent lateral flow as subgrid or "meta" hillslopes (Chaney et al. 2018; Swenson et al. 2019). This approach defines hillslopes with realistic length and height dimensions and assumes that a single hillslope or an ensemble of hillslopes are representative of the model grid cell. It is hence prudent to use simple synthetic test cases to evaluate the implementation of subsurface lateral flow.

The continuity equation for subsurface storage (below the water table) can be given in the $x$ dimension as (Wigmosta et al. 1994)

$$
\phi \frac{\partial z_{\mathrm{wt}}}{\partial t}=-\frac{\partial q_{x}}{\partial x} \frac{1}{x_{\mathrm{len}}}-q_{r},
$$

where $\phi(-)$ is the drainable porosity, $z_{\mathrm{wt}}(\mathrm{m})$ is the water table depth, $q_{x}\left(\mathrm{~m}^{3} \mathrm{~s}^{-1}\right)$ is the rate of saturated subsurface flow, $x_{\text {len }}$ (m) is the flow width, and $q_{r}\left(\mathrm{~m} \mathrm{~s}^{-1}\right)$ is the recharge flux.

Assuming an unconfined horizontal aquifer, the rate of saturated subsurface flow can be given as (Wigmosta and Lettenmaier 1999)

$$
q_{x}\left(z_{\mathrm{wt}}\right)=x_{\mathrm{len}} \tan \beta \mathcal{T}_{\mathrm{aq}}\left(z_{\mathrm{wt}}\right),
$$

where $\beta(-)$ is the water table slope and $\mathcal{T}_{\mathrm{aq}}\left(z_{\mathrm{wt}}\right)\left(\mathrm{m}^{2} \mathrm{~s}^{-1}\right)$ is the aquifer transmissivity at water table depth $z_{\mathrm{wt}}$. The transmissivity can be obtained from the vertical profile of saturated hydraulic conductivity, $k_{s}\left(\mathrm{~m} \mathrm{~s}^{-1}\right)$, e.g., using the power-law profile described by Rupp and Woods (2008), as

$$
k_{s}(z)=k_{s}^{0}\left(1-\frac{z}{z_{\max }}\right)^{n_{\mathrm{sf}}-1},
$$

where $k_{s}^{0}\left(\mathrm{~m} \mathrm{~s}^{-1}\right)$ is the saturated hydraulic conductivity at the soil surface, $z_{\max }$ is the depth of the soil profile, and $n_{\mathrm{sf}}$ is the shape of the transmissivity profile. The transmissivity is hence

$$
\mathcal{T}_{\mathrm{aq}}\left(z_{\mathrm{wt}}\right)=\int_{z_{\mathrm{wt}}}^{z_{\max }} k_{s}(w) d w
$$

yielding

$$
\mathcal{T}_{\mathrm{aq}}\left(z_{\mathrm{wt}}\right)=\frac{k_{s}^{0} z_{\mathrm{max}}}{n_{\mathrm{sf}}}\left(1-\frac{z_{\mathrm{wt}}}{z_{\mathrm{max}}}\right)^{n_{\mathrm{sf}}}, \quad n_{\mathrm{sf}} \geq 1,
$$




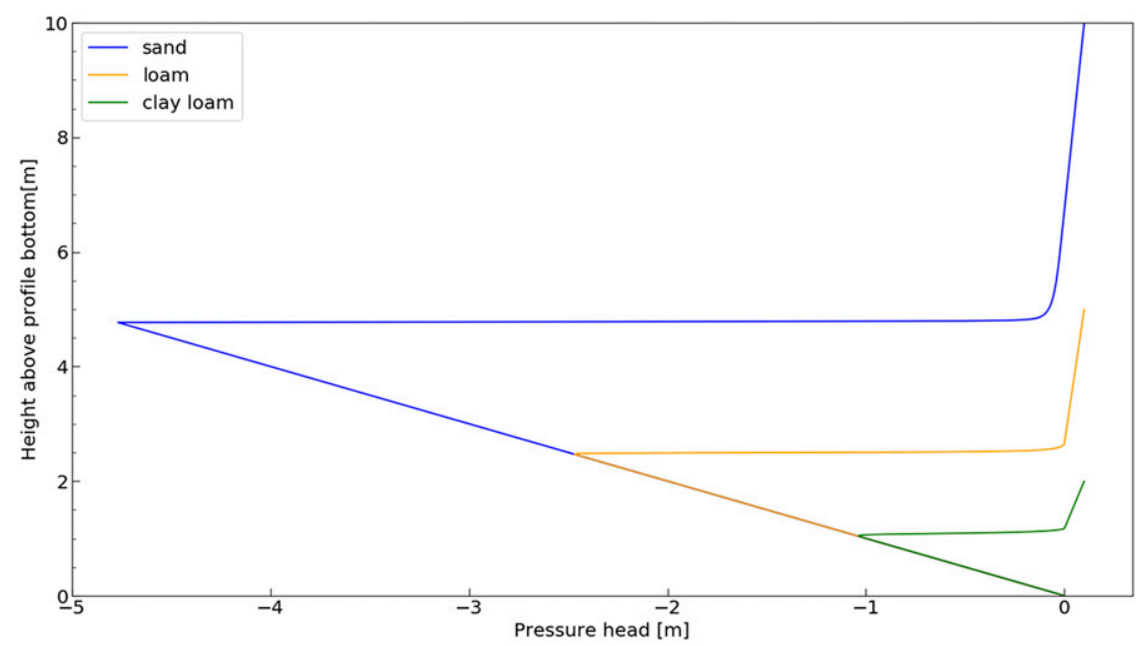

FIG. 3. Solution of the test problem from Miller et al. (1998), showing pressure profiles for sand at $t=0.18$ days, loam at $t=2.25$ days, and clay loam at $t=1$ day.

as used in some applications of TOPMODEL (Duan and Miller 1997). The subsurface lateral flow is included as part of the source-sink flux term in Eq. (2).

Here, we use the synthetic experiments described by Wigmosta and Lettenmaier (1999) to evaluate model representations of hillslope hydraulics under steady-state and transient conditions. The Wigmosta and Lettenmaier experiments provide a test for the conditions where topography dominates subsurface flow, i.e., steep hillslopes with thin, permeable soils. Under these conditions, the slope of the water table is assumed to be parallel to the ground surface, and saturated subsurface flow can be modeled using a kinematic wave equation. Such simplifications are useful because the kinematic wave equation can be solved analytically using the method of characteristics.

The Wigmosta and Lettenmaier test case applies a constant rainfall rate of $5.56 \mathrm{~kg} \mathrm{~m}^{-2} \mathrm{~s}^{-1}\left(0.002 \mathrm{~m} \mathrm{~h}^{-1}\right)$ for $550 \mathrm{~h}$ to an example hillslope of length $50 \mathrm{~m}$ and height $15 \mathrm{~m}$ (i.e., slope $\tan \beta=0.3$ ), with soil depth $z_{\max }=1.5 \mathrm{~m}$ and drainable porosity $\phi=0.25$. For this test case, we discretize the hillslope into 50 independent soil columns; the lateral flow across soil columns is represented using the lateral flow source-sink flux term, i.e., $S_{\text {lf }}$ defined in Eq. (20).

For this test case, we solve Eqs. (50)-(53), (55), (56), and (59) subject to the initial and boundary conditions

$$
\begin{aligned}
z_{\mathrm{wt}}(z, 0) & =1.5 \mathrm{~m}, \\
q_{\text {liq }}^{\text {soil }}(0, t) & =\left\{\begin{array}{cc}
0.002 \mathrm{~m} \mathrm{~h}^{-1}, & t \leq 550 \mathrm{~h}, \\
0, & t>550 \mathrm{~h},
\end{array}\right. \\
q_{\text {liq }}^{\text {soil }}\left(z_{\text {max }}, t\right) & =0 .
\end{aligned}
$$

The spatial domain spans a single hillslope consisting of 50 soil columns. Each soil column is vertically discretized into 8 soil layers. The simulation time consists of 1000 data windows of length $3600 \mathrm{~s}$ for a total simulation time of $1000 \mathrm{~h}$.

Figure 5 illustrates the simulated water table profiles and hillslope outflow for the following two experiments:
1) $n_{\mathrm{sf}}=1$ and $k_{\mathrm{s}}^{0}=8.33 \times 10^{-5} \mathrm{~m} \mathrm{~s}^{-1}\left(0.3 \mathrm{~m} \mathrm{~h}^{-1}\right)$ and

2) $n_{\mathrm{sf}}=3$ and $k_{s}^{0}=8.33 \times 10^{-4} \mathrm{~m} \mathrm{~s}^{-1}\left(3.0 \mathrm{~m} \mathrm{~h}^{-1}\right)$.

As in Wigmosta and Lettenmaier (1999), the model simulations have close correspondence to the analytical solutions.

\section{c. Coupled thermodynamic and hydrological processes in snow}

Snow modeling can be challenging because of the strong coupling between the thermodynamic and hydrological processes. For example, the propagation of liquid water in snow requires satisfying both thermal and liquid deficits. It requires both freezing a sufficient volume of water onto the snow grains to raise the snow temperature to $0^{\circ} \mathrm{C}$ as well as filling the storage of water that is retained as an adsorbed film and the water held immobile in the menisci between the snow grains (Colbeck 1976). It is useful to define test cases that evaluate these coupled processes.

As in Eqs. (8) and (2), the coupled conservation equations for energy and mass in snow can be defined by the state variables of temperature $T(\mathrm{~K})$ and volumetric fraction of total water $\Theta_{m}^{\text {snow }}$,

$$
C_{p} \frac{\partial T^{\text {snow }}}{\partial t}-L_{\text {fus }} \rho_{\text {ice }} \frac{\partial \theta_{\text {ice }}^{\text {snow }}}{\partial t}=-\frac{\partial F^{\text {snow }}}{\partial z}
$$

TABLE 3. Parameters for the soil types used in the Vanderborght et al. (2005) test cases.

\begin{tabular}{lccc}
\hline \hline Soil type & Sand & Loam & Clay \\
\hline$\theta_{r}(-)$ & 0.045 & 0.080 & 0.100 \\
$\theta_{s}(-)$ & 0.430 & 0.430 & 0.400 \\
$\alpha\left(\mathrm{m}^{-1}\right)$ & 15.000 & 4.000 & 1.000 \\
$n(-)$ & 3.000 & 1.600 & 1.100 \\
$m(-)$ & $1-(1 / n)$ & $1-(1 / n)$ & $1-(1 / n)$ \\
$k_{s}\left(\mathrm{~m} \mathrm{~s}^{-1}\right)$ & $1.16 \times 10^{-4}$ & $5.79 \times 10^{-6}$ & $1.16 \times 10^{-6}$ \\
$S_{s}\left(\mathrm{~m}^{-1}\right)$ & $10^{-6}$ & $10^{-6}$ & $10^{-6}$ \\
\hline
\end{tabular}



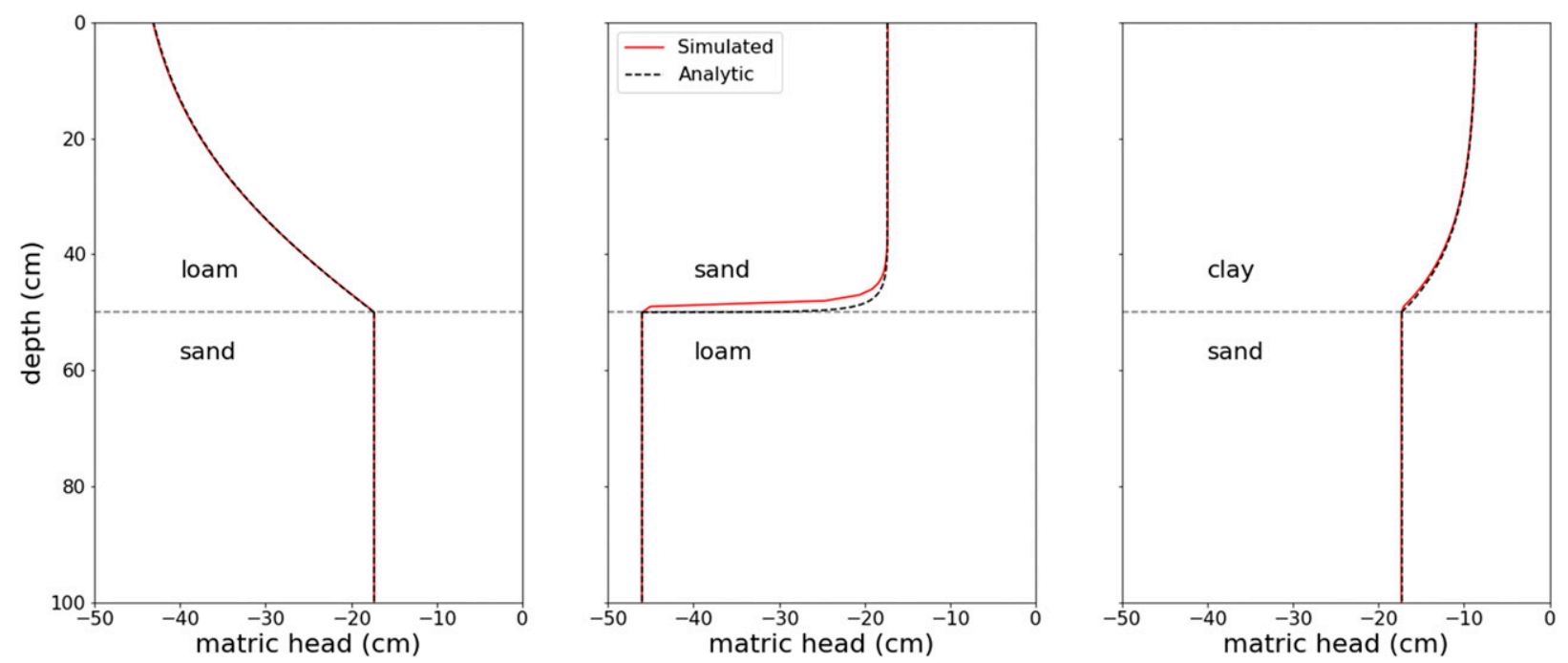

FIG. 4. Solution of the three test problems from Vanderborght et al. (2005), showing the vertical profiles of pressure head at steady state. The solid red lines are the model simulations, and the dashed black lines are the analytical solutions.

$$
\frac{\partial \Theta_{m}^{\text {snow }}}{\partial t}=-\frac{\partial q_{\mathrm{liq}}^{\text {snow }}}{\partial z} .
$$

The volumetric fraction of liquid water is

$$
\theta_{\text {liq }}^{\text {snow }}\left(T^{\text {snow }}, \Theta_{m}^{\text {snow }}\right)=\left\{\begin{array}{cl}
\frac{\Theta_{m}^{\text {snow }}}{1+\left[\varpi\left(T_{\text {frz }}-T^{\text {snow }}\right)\right]^{2}}, & T^{\text {snow }}<T_{\text {frz }}, \\
\Theta_{m}^{\text {snow }}, & T^{\text {snow }} \geq T_{\text {frz }},
\end{array}\right.
$$

with $T_{\mathrm{frz}}=273.16 \mathrm{~K}$ the triple point of pure water and $\varpi\left(\mathrm{K}^{-1}\right)$ is a scaling parameter. Equation (62) defines a smoothed step function over a small temperature interval below $T_{\text {frz }}$, ranging from zero to $\Theta_{m}^{\text {snow }}$ at $T_{\text {frz }}$. The parameter $\varpi$ defines the degree of smoothing (e.g., $\varpi=50 \mathrm{~K}^{-1}$ defines a function that is visually indistinguishable from a step function over a typical diurnal temperature range).

The vertical liquid flux in snow is related to the volumetric fraction of liquid water; i.e.,

$$
q_{\mathrm{liq}}^{\text {snow }}=\left\{\begin{array}{cl}
0, & \theta_{\mathrm{liq}}^{\text {snow }} \leq \theta_{r}, \\
k_{s}^{\text {snow }}\left(\frac{\theta_{\mathrm{liq}}^{\text {snow }}-\theta_{r}}{\theta_{s}-\theta_{r}}\right)^{n_{s}}, & \theta_{\mathrm{liq}}^{\text {snow }}>\theta_{r},
\end{array}\right.
$$

where $k_{s}^{\text {snow }}\left(\mathrm{m} \mathrm{s}^{-1}\right)$ is the saturated hydraulic conductivity, $\theta_{r}$ is the residual volumetric liquid water content, $\theta_{s}=1-\theta_{\text {ice }}^{\text {snow }}$ is the porosity, and $n_{s}$ defines the shape of the hydraulic conductivity function. The saturated hydraulic conductivity is given as

$$
k_{s}^{\text {snow }}=\kappa \frac{\rho_{\text {liq }} g}{\mu},
$$

where $\kappa\left(\mathrm{m}^{2}\right)$ is the permeability, $g\left(\mathrm{~m} \mathrm{~s}^{-2}\right)$ is the gravitational acceleration, and $\mu\left(\mathrm{kg} \mathrm{m}^{-1} \mathrm{~s}^{-1}\right)$ is the dynamic viscosity. The values of these parameters are given in Table 4.
Here, we use the synthetic experiments of water movement through snow that were introduced by Colbeck (1976) and further developed by Clark et al. (2017). Colbeck (1976) considered a constant rain rate of $0.1 \mathrm{~kg} \mathrm{~m}^{-2} \mathrm{~s}^{-1}$ applied at the top of a 1-m snowpack for a time period of $3 \mathrm{~h}$ for different initial snow conditions: ripe snow, refrozen snow, and fresh snow (see Table 5). The colder initial temperatures for refrozen and fresh snow require that both the heat deficit and the residual saturation deficit be satisfied before flow occurs; the smaller grain size for fresh snow substantially reduces the permeability of the snowpack and slows the flow of water. Colbeck's examples provide a useful test case for snow models because they evaluate the coupling of hydrology and thermodynamics (i.e., the freezing of water onto the snow grains necessary to supply sufficient latent heat to raise the snow temperature to $0^{\circ} \mathrm{C}$ ), as well as providing a means to evaluate the unsaturated flow of water through porous media.

For these test cases, we solve Eqs. (60)-(64) subject to the boundary conditions

$$
\begin{aligned}
q_{\mathrm{liq}}^{\text {snow }}(0, t) & =\left\{\begin{array}{cl}
0.1, & 0 \leq t<10800 \mathrm{~s}, \\
0, & t>10800 \mathrm{~s},
\end{array}\right. \\
F(0, t) & =0 \\
F(1, t) & =0
\end{aligned}
$$

with initial conditions given in Table 5 .

The snow domain is discretized into 100 uniform layers, and the simulation time consists of 600 data windows of length $60 \mathrm{~s}$ for a total simulation time of $10 \mathrm{~h}$.

The solutions for the test cases for water movement through snow are presented in Figs. 6 and 7 along with analytical solutions derived using the method of characteristics [see Clark et al. (2017) for full development of the analytical solutions]. As presented earlier by Clark et al. 

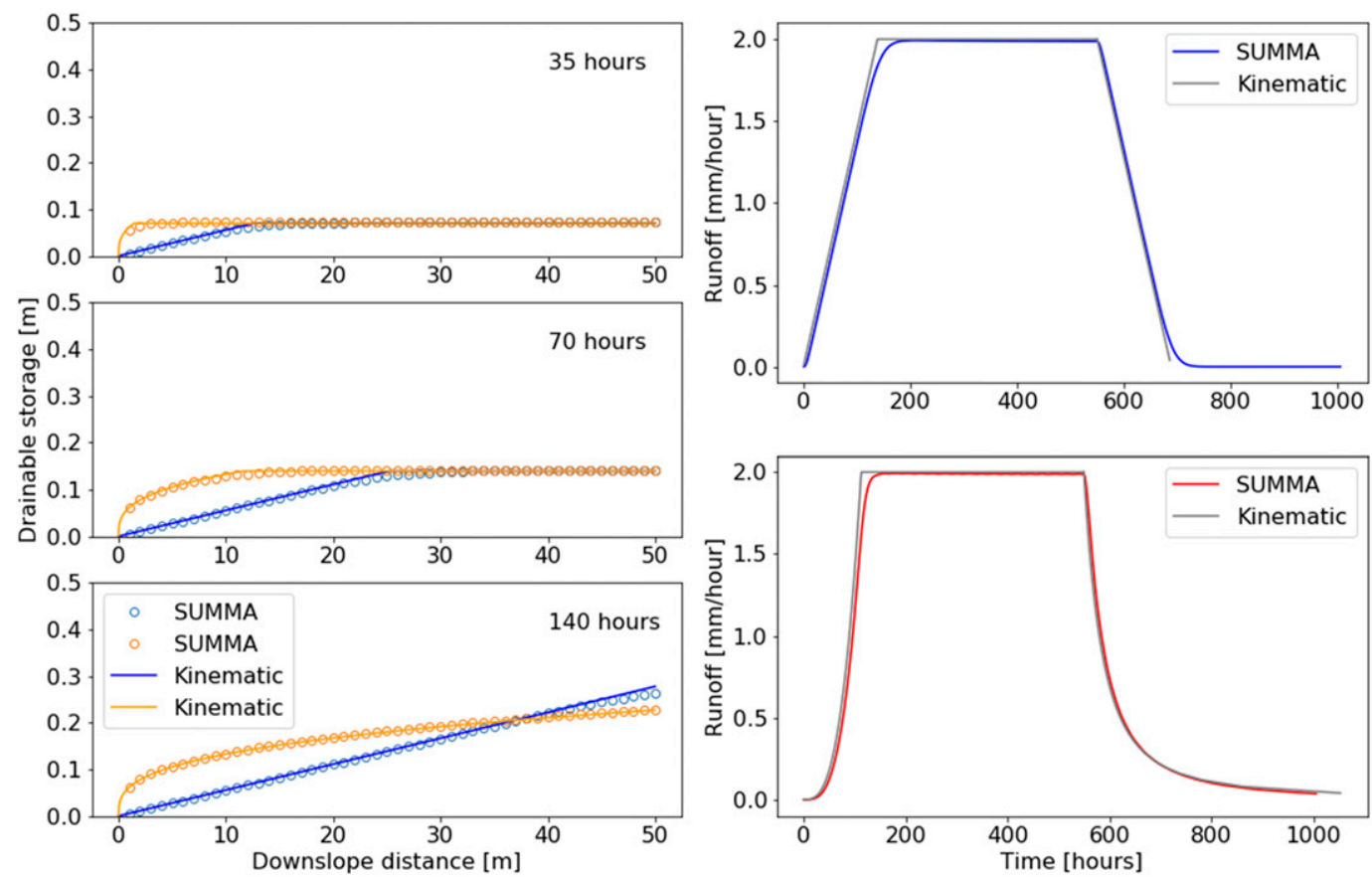

FIG. 5. Simulated (left) water table profiles and (right) hillslope outflow for the test problems from Wigmosta and Lettenmaier (1999). The figure shows both the linear experiment $\left(n_{\mathrm{sf}}=1\right.$, blue $)$ and the nonlinear experiment $\left(n_{\mathrm{sf}}=\right.$ 3 , red).

(2017), the results in Fig. 6 demonstrate close correspondence between the numerical simulations and the analytical solutions, building confidence in the numerical model implementation. The results in Fig. 7 also show similar results in the numerical simulations and the analytical solutions, with numerical diffusion causing some water to flow from the bottom of the snowpack ahead of the wetting front.

\section{d. Cryosuction processes in soil}

The coupled thermodynamic and hydrological processes in soil cause the migration of water toward the freezing front, known as cryosuction (Hansson et al. 2004; Dall'Amico et al. 2011). Specifically, freezing of water in soil pores results in a low-pressure head, creating a gradient in pressure in the vicinity of the freezing front. Such cryosuction processes provide an interesting test case for land models because their solution requires accurate coupling of thermodynamic and hydrological processes as well as generating negative pressures that induce hydraulic gradients toward the freezing front.

Cryosuction processes can be simulated in a similar way to the coupled thermodynamic and hydrological processes in snow. Making use of Eqs. (1) and (15), the conservation equations for partially frozen soils can be written as

$$
\begin{aligned}
C_{p}^{\text {soil }} \frac{\partial T^{\text {soil }}}{\partial t}-L_{\text {fus }} \rho_{\text {ice }} \frac{\partial \theta_{\text {ice }}^{\text {soil }}}{\partial t} & =-\frac{\partial F^{\text {soil }}}{\partial z} \\
\frac{d \Theta_{m}^{\text {soil }}}{d \psi_{0}} \frac{\partial \psi_{0}}{\partial t} & =-\frac{\partial q_{\text {liq }}^{\text {soil }}}{\partial z}
\end{aligned}
$$

where, as in Eq. (15), $\psi_{0}(\mathrm{~m})$ is the matric potential that corresponds to the volumetric fraction of total water $\Theta_{m}^{\text {soil }}$. Equation (66) does not include the compressibility term in Eq. (15) because we restrict attention to unsaturated flow. The total water content in Eq. (66) is computed using the closure relation $\Theta_{m}^{\text {soil }}\left(\psi_{0}\right)=S_{*}\left(\psi_{0}\right)$, i.e., Eq. (16), where $S_{*}(\cdot)$ is a soilwater-retention function, e.g., the van Genuchten function Eq. (52). The term $d \Theta_{m}^{\text {soil }} / d \psi_{0}$ in Eq. (66) is the derivative of the closure relation.

We use the generalized Clapeyron equation to separate the volumetric fraction of total water into the volumetric fractions of liquid water and ice. The Clapeyron equation can be defined for the state of water as [Dall'Amico et al. 2011, their Eq. (11)]

$$
\frac{d P_{w}}{d T}=\frac{L_{\mathrm{fus}} \rho_{\mathrm{liq}}}{T}, \quad T<T_{*},
$$

TABLE 4. Physical constants and parameter values for the water flow examples presented by Colbeck (1976).

\begin{tabular}{lc}
\hline \hline$\rho_{\text {liq }}\left(\mathrm{kg} \mathrm{m}^{-3}\right)$ & 1000 \\
$\rho_{\text {ice }}\left(\mathrm{kg} \mathrm{m}^{-3}\right)$ & 917 \\
$\rho_{\text {air }}\left(\mathrm{kg} \mathrm{m}^{-3}\right)$ & 1.293 \\
$c_{\text {liq }}\left(\mathrm{J} \mathrm{kg}^{-1} \mathrm{~K}^{-1}\right)$ & 4181 \\
$c_{\text {ice }}\left(\mathrm{J} \mathrm{kg}^{-1} \mathrm{~K}^{-1}\right)$ & 2114 \\
$c_{\text {air }}\left(\mathrm{J} \mathrm{kg}^{-1} \mathrm{~K}^{-1}\right)$ & 1005 \\
$L_{\text {fus }}\left(\mathrm{J} \mathrm{kg}^{-1}\right)$ & 333700 \\
$\varpi(-)$ & 50 \\
$n_{\text {sf }}(-)$ & 3 \\
$\mu\left(\mathrm{kg} \mathrm{m}^{-1} \mathrm{~s}^{-1}\right)$ & $1.781 \times 10^{-3}$ \\
\hline
\end{tabular}


TABLE 5. Initial snow conditions and parameter values for the water flow examples presented by Colbeck (1976). See Clark et al. (2017) for more details.

\begin{tabular}{lccc}
\hline \hline \multicolumn{1}{c}{ Snow condition } & Ripe snow & Refrozen snow & Fresh snow \\
\hline Snow density $\left(\mathrm{kg} \mathrm{m}^{-3}\right)$ & 300 & 300 & 300 \\
Grain size $(\mathrm{mm})$ & 2 & 2 & 0.2 \\
$T^{\text {snow }}(z, 0)(\mathrm{K})$ & 273.116 & 268.16 & 268.16 \\
$\kappa(\mathrm{m})$ & $2.967 \times 10^{-8}$ & $2.967 \times 10^{-8}$ & $2.967 \times 10^{-10}$ \\
$\theta_{\text {liq }}^{\text {snow }}(z, 0)(-)$ & 0.051 & 0.000 & 0.000 \\
$\theta_{\text {ice }}^{\text {sico }}(z, 0)(-)$ & 0.272 & 0.327 & 0.327 \\
\hline
\end{tabular}

where $P_{w}(\mathrm{~Pa})$ is the water pressure, $T_{*}(\mathrm{~K})$ is the soil temperature where all water is unfrozen (note $T_{*}<T_{\mathrm{frz}}$ ), and all other variables are as defined previously. The liquid water matric potential from the Clapeyron equation can then be computed during subfreezing conditions. Given $P_{w}=\rho_{\text {liq }} g \psi$ and noting that $T_{*}=T_{\text {frz }}$ at $\psi=0$; i.e., $\psi\left(T_{\text {frz }}\right)=0$, Eq. (67) can be approximated as

$$
\frac{\psi(T)-\psi\left(T_{\mathrm{frz}}\right)}{T-T_{\mathrm{frz}}}=\frac{L_{\mathrm{fus}}}{g T_{\mathrm{frz}}}, \quad T<T_{*} .
$$

The liquid water matric potential from the Clapeyron equation, $\psi_{c}$, is then

$$
\psi_{c}(T)=\frac{L_{\mathrm{fus}}}{g} \frac{T-T_{\mathrm{frz}}}{T_{\mathrm{frz}}}, \quad T<T_{*} .
$$

We note that all water is unfrozen when $\psi_{0}<\psi_{c}$. Derivations of Eq. (69) are provided in Dall'Amico et al. (2011) and Painter and Karra et al. (2014).

Using the "freezing = drying" assumption (Spaans and Baker 1996), i.e., the same closure relations for soil-waterretention and hydraulic conductivity, Eqs. (52) and (53) can be used under both freezing and drying conditions, $\psi_{c}$ can be used to separate $\Theta_{m}^{\text {soil }}$ into the volumetric fractions of liquid water and ice. The soil freezing temperature, $T_{*}$, used to delineate unfrozen and partially frozen conditions, can be
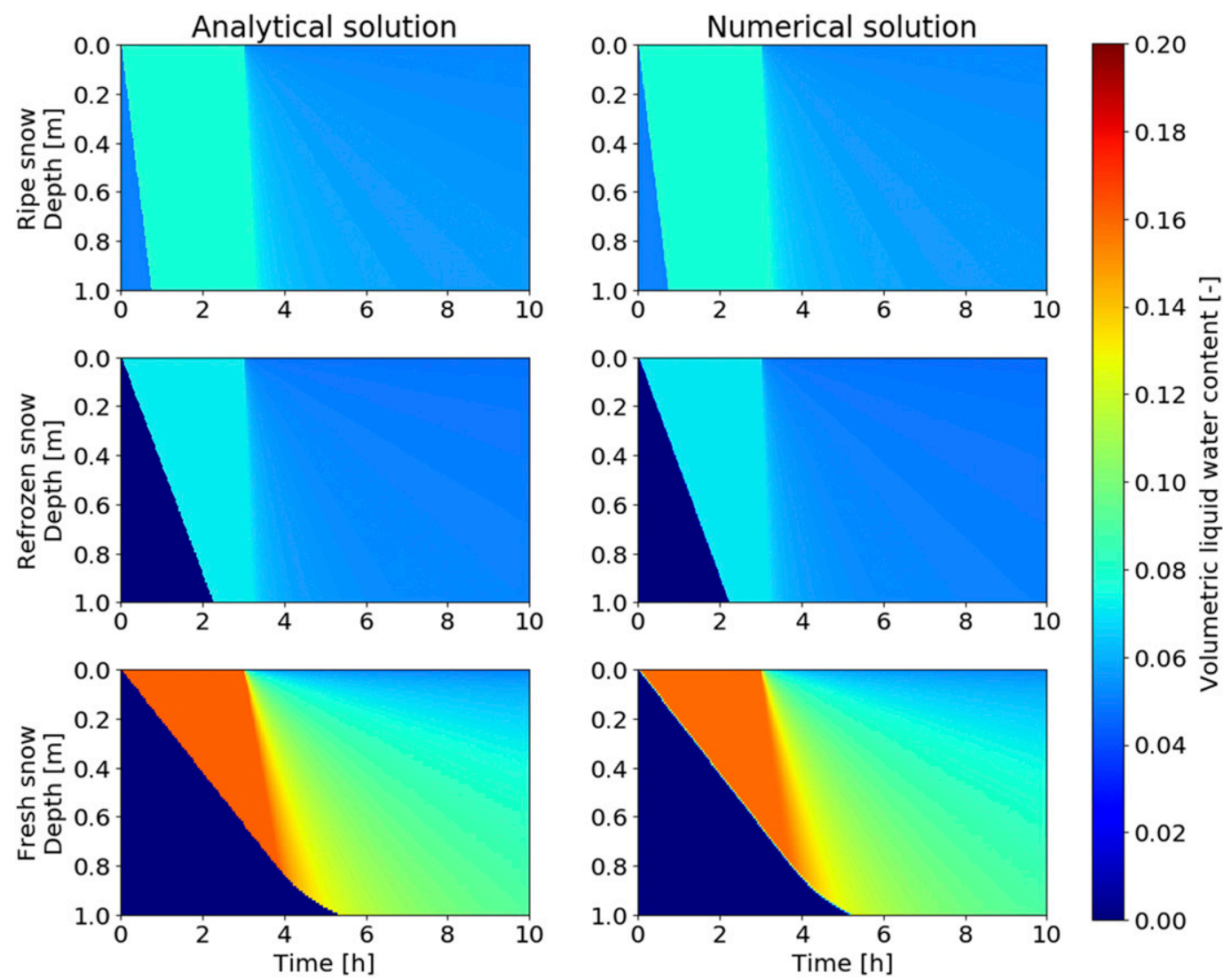

FIG. 6. Contour plots of the volumetric fraction of liquid water for the problem of Colbeck (1976) from (left) the analytical solution and (right) the numerical simulations for (top) the ripe snow test case, (middle) the refrozen snow test case, and (bottom) the fresh snow test case. 

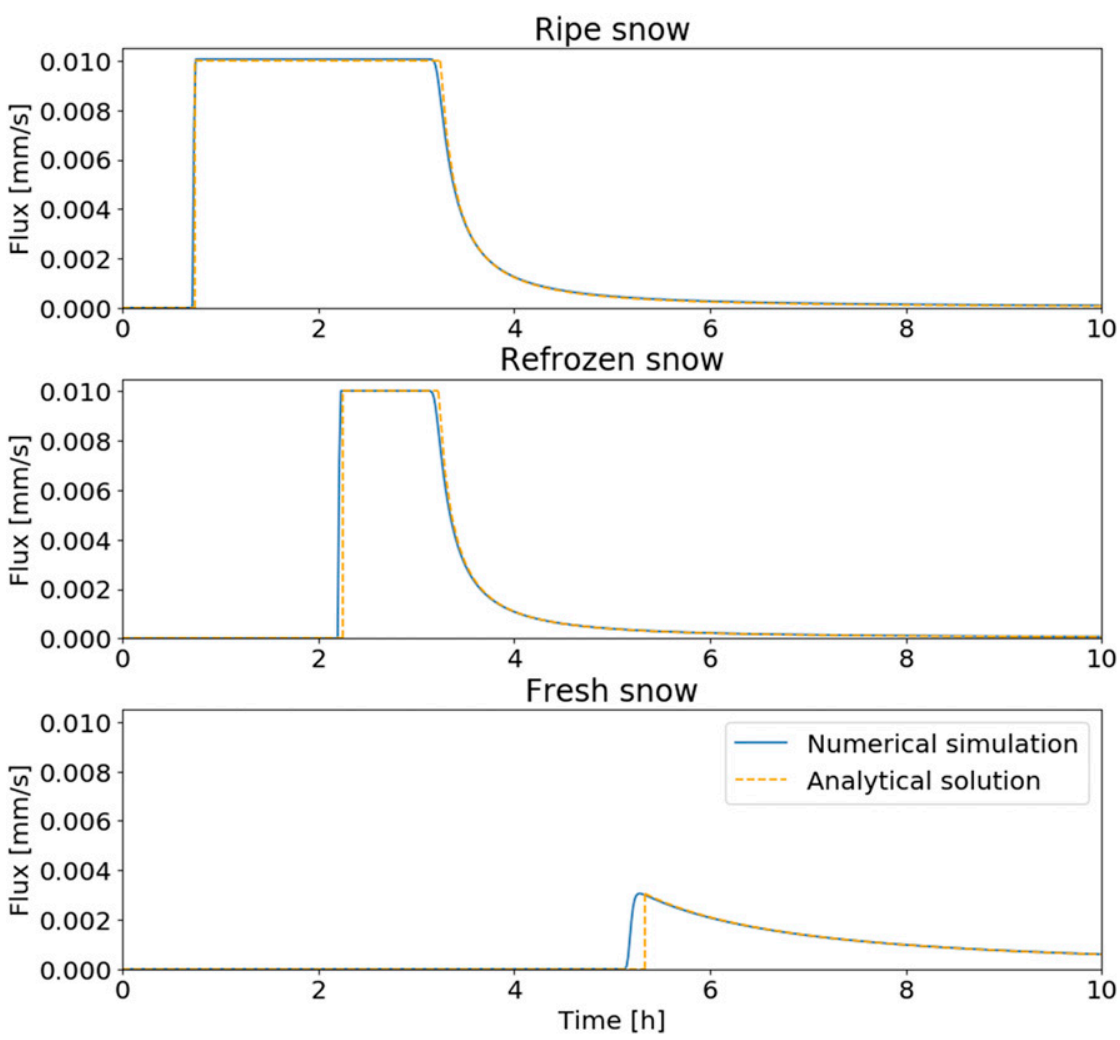

FIG. 7. The outflow hydrograph for the problem of Colbeck (1976) from numerical simulations (solid lines) and analytical solutions (dashed lines) for (top) the ripe snow test case, (middle) the refrozen snow test case, and (bottom) the fresh snow test case.

obtained by setting $\psi_{c}=\psi_{0}$ in Eq. (69) and solving for $T_{*}$ as a function of $\psi_{0}$ :

$$
T_{*}\left(\psi_{0}\right)=\left\{\begin{array}{cc}
T_{\mathrm{frz}}, & \psi_{0}>0, \\
T_{\mathrm{frz}}+\frac{g T_{\mathrm{frz}}}{L_{\mathrm{fus}}} \psi_{0}, & \psi_{0} \leq 0,
\end{array}\right.
$$

and the volumetric fraction of liquid water computed using a soil-water-retention function, $S_{*}(\cdot)$,

$$
\theta_{\mathrm{liq}}^{\text {soil }}\left(\psi_{0}, T\right)= \begin{cases}S_{*}\left(\psi_{c}\right), & T<T_{*}, \\ S_{*}\left(\psi_{0}\right), & T \geq T_{*}\end{cases}
$$

The volumetric fraction of ice can then be defined based on the volume constraints

$$
\begin{gathered}
\theta_{\text {air }}^{\text {soil }}\left(\psi_{0}\right)=\theta_{s}-S_{*}\left(\psi_{0}\right) \text { and } \\
\theta_{\text {ice }}^{\text {soil }}\left(\psi_{0}, T\right)=\theta_{s}-\theta_{\text {air }}^{\text {soil }}\left(\psi_{0}\right)-\theta_{\text {liq }}^{\text {soil }}\left(\psi_{0}, T\right) .
\end{gathered}
$$

In this approach, it is assumed that the intrinsic density of ice in soil is equal to the intrinsic density of liquid water, i.e., $\rho_{\text {ice }}=$ $1000 \mathrm{~kg} \mathrm{~m}^{-3}$, and hence $\Theta_{m}^{\text {soil }}=\theta_{\text {liq }}^{\text {soil }}+\theta_{\text {ice }}^{\text {soil }}$. This assumption avoids the need for a mechanical model to handle the deformation of the soil matrix caused by volume expansion during freezing [this assumption was also made by Dall'Amico et al. (2011)].
The vertical fluxes of water in soil, $q_{\mathrm{liq}}^{\text {soil }}$ used in Eq. (66), can (in principle) be computed from Eqs. (51) and (69), i.e., $q_{\text {liq }}^{\text {soil }}\left(\psi_{\mathrm{c}}\right)$. In practice, however, this procedure creates two practical issues: first, the presence of ice may substantially reduce the liquid water flux due to the apparent pore blockage effect exerted by ice (Dall'Amico et al. 2011); second, $\psi_{c}$ can have large negative values (substantial suction) as the volumetric fraction of air approaches zero, and this behavior can complicate the numerical solution. A common approach to address these issues is to apply a multiplicative ice impedance factor to the hydraulic conductivity function, e.g., Eq. (53). Specifically, to solve Eq. (66), previous studies have used a modified hydraulic conductivity function $\tilde{k}\left(\psi_{\mathrm{c}}\right)=10^{-\zeta \nu} k\left(\psi_{\mathrm{c}}\right)$ with parameter $\zeta$ (e.g., $\zeta=7$ ) and $\nu=\theta_{\text {ice }}^{\text {soil }} / \theta_{s}-\theta_{r}$ (e.g., Hansson et al. 2004; Dall'Amico et al. 2011).

Here, we implement an alternative modification to the vertical flux parameterizations. We follow the approach of Zhao et al. (1997) and only use the Clapeyron equation to separate the phases of liquid water and ice within soil (i.e., $\psi_{c} \neq \psi$ ). The liquid water matric potential $\psi(\mathrm{m})$, is computed by assuming that ice forms part of the solid matrix (Zhao et al. 1997). The effective saturation of soils $S_{e}(-)$ is

$$
S_{e}\left(\psi_{0}, T\right)=\frac{\theta_{\text {liq }}^{\text {soil }}-\theta_{r}}{\theta_{s}-\theta_{\text {ice }}^{\text {soil }}-\theta_{r}},
$$



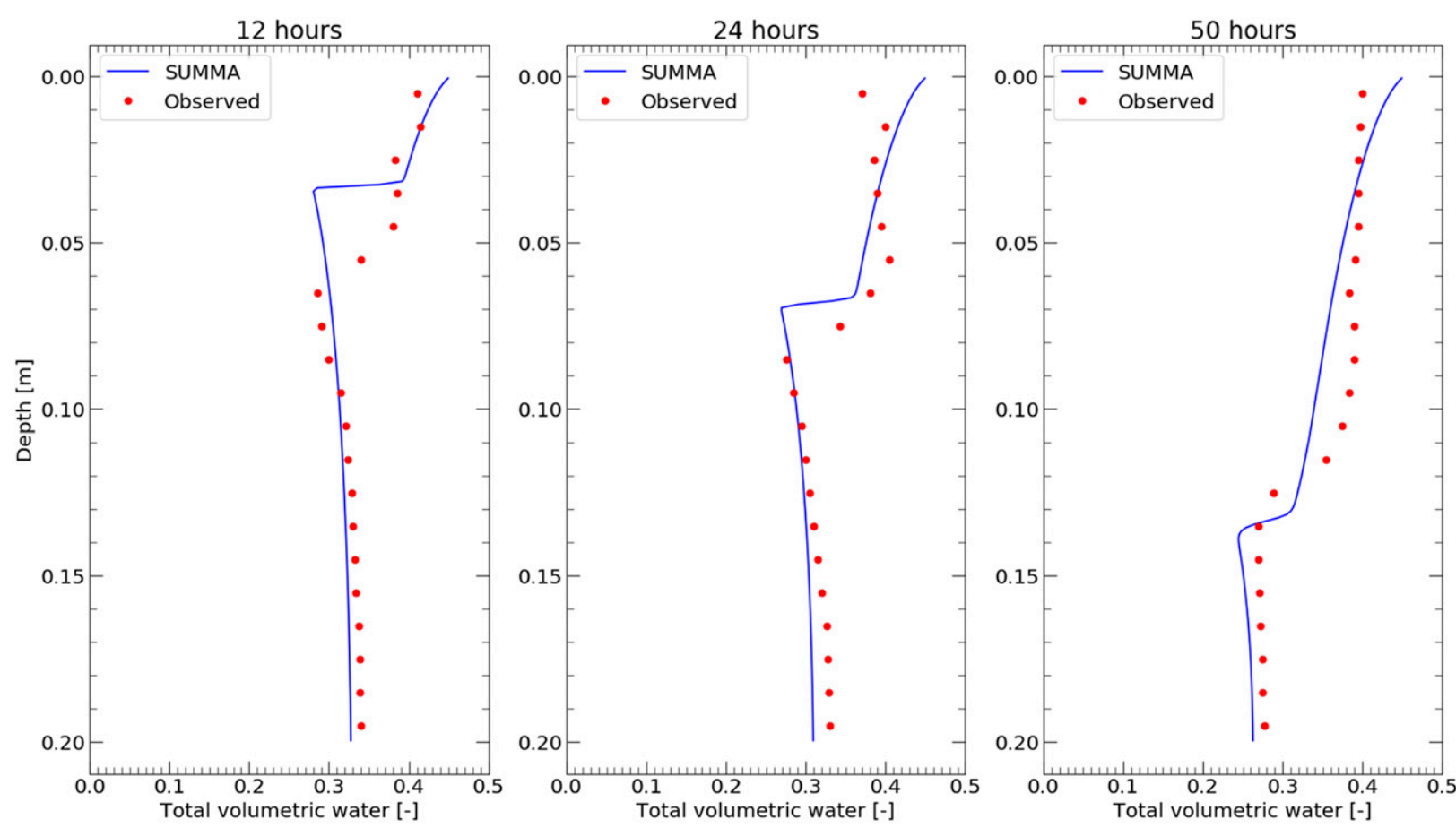

FIG. 8. Simulated and measured values of the total volumetric water content for the Mizoguchi experiment for (left) $12 \mathrm{~h}$, (center) $24 \mathrm{~h}$, and (right) $50 \mathrm{~h}$ after the start of the experiment.

and using the soil-water-retention function, e.g., Eq. (52),

$$
\psi\left(\psi_{0}, T\right)=\frac{1}{\alpha}\left(S_{e}^{-1 / m}-1\right)^{1 / n}
$$

and $q_{\mathrm{liq}}^{\text {soil }}(\psi)$ can be computed using Eq. (51). Including ice as part of the solid matrix both reduces suction when ice is present (i.e., it impedes flow) and also simplifies the numerical solution because $\psi \rightarrow 0$ as $\theta_{\text {air }}^{\text {soil }} \rightarrow 0$. Although more complex approaches are available (e.g., Karra et al. 2014), the simple modification to the flux parameterization described here is straightforward to implement in most land models.

We use the laboratory experiments of Mizoguchi (1990) to evaluate cryosuction processes. These experiments are described in detail (and in English) by Hansson et al. (2004). Briefly, Mizoguchi packed four identical cylinders $(8-\mathrm{cm}$ diameter, 20-cm length) with sandy loam and brought them to the same initial state of uniform temperature of $6.7^{\circ} \mathrm{C}$ and close to uniform volumetric liquid water content of 0.33 . One of the cylinders was excluded from the freezing tests; the other cylinders were insulated on the sides and bottom and subjected to a circulating fluid with temperature $-6^{\circ} \mathrm{C}$ at the top. The cylinders were removed from the freezing apparatus after 12,24 , and $50 \mathrm{~h}$, divided into 1 - $\mathrm{cm}$ slices, and dried in an oven to obtain volumetric fraction of total water (liquid plus ice). The experiments demonstrated redistribution of water to the top of the soil column. Soil hydraulic parameters for the Mizoguchi case are $k_{s}=3.2 \times 10^{-6} \mathrm{~m} \mathrm{~s}^{-1}$, $\theta_{r}=0.05, \theta_{s}=0.535, \alpha=1.11\left(\mathrm{~m}^{-1}\right)$, and $n=1.48$. We solve Eqs. (65), (66), and (69)-(75) subject to the initial and boundary conditions

$$
\begin{aligned}
\Theta_{m}^{\text {soil }}(z, 0) & =0.33, & T(z, 0) & =6.7^{\circ} \mathrm{C}, \\
q_{\text {liq }}^{\text {soil }}(0, t) & =0, & T(0, t) & =-6.0^{\circ} \mathrm{C}, \\
q_{\text {liq }}^{\text {soil }}(0.2, t) & =0, & F(0.2, t) & =0 .
\end{aligned}
$$

The soil domain is discretized into 200 uniform layers, and the simulation time consists of 3600 data windows of length $60 \mathrm{~s}$ for a total simulation time of $60 \mathrm{~h}$.

Figure 8 compares model simulations to the observations from the Mizoguchi experiment. Similar to the simulations presented by Hansson et al. (2004) and Dall'Amico et al. (2011), the model simulations and laboratory measurements both show the redistribution of water toward the top of the soil profile.

\section{Energy and water balance}

All of the test problems described in this paper enable evaluating the coupled processes in the different model subdomains. A fundamental metric that is relevant for all of the numerical experiments is whether the numerical methods conserve energy and mass. To this end, we evaluate the energy and mass balance for all of the test problems.

\section{a. Energy balance}

The energy balance error $\varepsilon_{\mathrm{nrg}_{j, n}}^{\Omega}$ for Eq. (1) is

$$
\varepsilon_{\mathrm{nrg}_{j, n}}^{\Omega}=\Delta H_{T_{j, n+1}}^{\Omega} \Delta z_{j}^{\Omega}-\overline{F_{\text {net }_{j}}^{\Omega}} \Delta t_{n}, \Omega=\text { snow, soil },
$$

where, as in Eqs. (41) and (43), $\Delta H_{T_{j, n+1}}^{\Omega}=H_{T_{j}}^{\Omega}\left(t_{n+1}\right)-H_{T_{j}}^{\Omega}\left(t_{n}\right)$ and 
TABLE 6. Statistics of the energy balance errors $\left(\mathrm{J} \mathrm{m}^{-2}\right)$ : $\left\|\varepsilon_{\mathrm{nrg}}^{\Omega}\right\|_{\infty}=\max _{n}\left|\varepsilon_{\mathrm{nrg}}^{\Omega}\right|$ is the maximum absolute energy balance error and $\left\|\varepsilon_{\mathrm{nrg}}^{\Omega}\right\|_{1} / n=\sum_{n}\left|\varepsilon_{\mathrm{nrg}_{n}}^{\Omega}\right| / n$ is the mean absolute energy balance error.

\begin{tabular}{llcc}
\hline \hline Test problem & Domain & $\left\|\varepsilon_{\text {nrg }}^{\Omega}\right\|_{\infty}$ & $(1 / n)\left\|\varepsilon_{\text {nrg }}^{\Omega}\right\|_{1}$ \\
\hline Colbeck expt 1 & $\Omega=$ snow & 0.215551 & 0.000423 \\
Colbeck expt 2 & $\Omega=$ snow & 0.019439 & 0.001423 \\
Colbeck expt 3 & $\Omega=$ snow & 0.329533 & 0.023033 \\
Mizoguchi & $\Omega=$ soil & 0.002333 & 0.000006 \\
\hline
\end{tabular}

$$
\overline{F_{\text {net }_{j}}^{\Omega}} \Delta t_{n}=\int_{t_{n}}^{t_{n+1}} F_{\text {net }_{j, t}}^{\Omega} d t .
$$

The net fluxes $F_{\text {net }_{j}}^{\Omega}$ in Eq. (77) are defined in Eq. (42). The SUNDIALS solver provides variable-order approximations of $\overline{F_{\text {net }}}$; ; we note that the first-order implicit Euler method corresponds to the approximation of $\overline{F_{\text {net }_{j}}^{\Omega}}$ by $F_{\text {net }_{j, n+1}}^{\Omega}$ (i.e., the right-hand rectangle rule). The energy source-sink flux term $\mathcal{F}_{\text {sink }}^{\Omega}$ in Eq. (1) is omitted because $\mathcal{F}_{\text {sink }}^{\Omega}=0$ in all test problems presented. Formulating Eq. (76) with $\Delta z_{j}^{\Omega}$ included in the first term on the RHS accounts for the compaction of snow layers. The total energy balance error for the snow or soil domain for time step $n$ is then

$$
\varepsilon_{\mathrm{nrg}_{n}}^{\Omega}=\sum_{j=1}^{j^{\Omega}} \varepsilon_{\mathrm{nrg}_{j, n}}
$$

The statistics of the energy balance errors are quantified in Table 6 using the maximum absolute energy balance error $\left\|\varepsilon_{\mathrm{nrg}}^{\Omega}\right\|_{\infty}=\max _{n}\left|\varepsilon_{\mathrm{nrg}_{n}}^{\Omega}\right|$ and the mean absolute energy balance error $\left\|\varepsilon_{\mathrm{nrg}}^{\Omega}\right\|_{1} / n=\sum_{n}\left|\varepsilon_{\mathrm{nrg}_{n}}^{\Omega}\right| / n$.

\section{b. Water balance}

The water balance error in Eqs. (2) and (15) for the snow and soil domains is

$$
\begin{aligned}
& \varepsilon_{\text {mass }_{j, n}}^{\text {snow }}=\Delta \Theta_{m_{j, n+1}}^{\text {snow }} \Delta z_{j}^{\text {snow }}-\overline{q_{\text {net }_{j}}^{\text {snow }}} \Delta t_{n}, \Omega=\text { snow } \\
& \varepsilon_{\text {mass }_{j, n}}^{\text {soil }}=\left(\Delta \Theta_{m_{j, n+1}}^{\text {soil }}+S_{s} \frac{\Theta_{m_{j, n+1}}^{\text {soil }}}{\theta_{s_{j}}} \Delta \psi_{0_{j, n+1}}\right) \Delta z_{j}-\overline{q_{\text {net }_{j}}^{\text {soil }}} \Delta t_{n}, \Omega=\text { soil },
\end{aligned}
$$

where $\Delta \psi_{0_{j, n+1}}=\psi_{0_{j}}\left(t_{n+1}\right)-\psi_{0_{j}}\left(t_{n}\right), \Delta \Theta_{m_{j, n+1}}^{\Omega}=\Theta_{m_{j}}^{\Omega}\left(t_{n+1}\right)-\Theta_{m_{j}}^{\Omega}$ $\left(t_{n}\right)$, and

$$
\overline{q_{\mathrm{net}_{j}}^{\Omega}} \Delta t_{n}=\int_{t_{n}}^{t_{n+1}} q_{\mathrm{net}_{j}}^{\Omega} d t, \Omega=\text { snow, soil },
$$

where $q_{\text {net }_{j}}^{\Omega}-\left[\left(q_{\mathrm{liq}^{\Omega}}^{\Omega}\right)_{j+1 / 2}-\left(q_{\mathrm{liq}}^{\Omega}\right)_{j-1 / 2}\right]$. As in Eq. (77), we note that the SUNDIALS solver provides variable-order approximations of $\overline{q_{\mathrm{net}_{j}}^{\Omega}}$ and that the first-order implicit Euler method corresponds to the approximation of $\overline{q_{\text {net }_{j}}^{\Omega}}$ by $q_{\text {net }_{j, n+1}}^{\Omega}$. In Eq. (81), the source-sink flux term $\mathcal{M}_{\text {sink }}^{\Omega}$ is omitted because $\mathcal{M}_{\text {sink }}^{\Omega}=0$ in all test problems. Moreover, Eq. (81) ignores the vertical flux of ice (i.e., snowfall and sublimation) because these fluxes are also not included in the test problems. As in Eq. (76), the total mass balance error for the snow and soil domains for time step $n$ is
TABLE 7. Statistics of the mass balance errors $\left(\mathrm{kg} \mathrm{m}^{-2}\right)$ : $\left\|\varepsilon_{\text {mass }}^{\Omega}\right\|_{\infty}=\max _{n}\left|\varepsilon_{\text {mass }}^{\Omega}\right|$ is the maximum absolute mass balance error and $\left\|\varepsilon_{\text {mass }}^{\Omega}\right\|_{1} / n=\sum_{n}\left|\varepsilon_{\text {mass }_{n}}^{\Omega}\right| / n$ is the mean absolute mass balance error.

\begin{tabular}{llll}
\hline \hline \multicolumn{1}{c}{ Test problem } & Domain & \multicolumn{1}{c}{$\left\|\varepsilon_{\text {mass }}^{\Omega}\right\|_{\infty}$} & $(1 / n)\left\|\varepsilon_{\text {mass } 1}^{\Omega}\right\|$ \\
\hline Celia & $\Omega=$ soil & $2.14 \times 10^{-15}$ & $5.18 \times 10^{-16}$ \\
Miller clay & $\Omega=$ soil & $1.63 \times 10^{-6}$ & $4.03 \times 10^{-8}$ \\
Miller loam & $\Omega=$ soil & $1.38 \times 10^{-13}$ & $8.97 \times 10^{-15}$ \\
Miller sand & $\Omega=$ soil & $1.07 \times 10^{-11}$ & $2.51 \times 10^{-13}$ \\
Vanderborght expt 1 & $\Omega=$ soil & $6.14 \times 10^{-9}$ & $6.14 \times 10^{-9}$ \\
Vanderborght expt 2 & $\Omega=$ soil & $9.89 \times 10^{-9}$ & $9.89 \times 10^{-9}$ \\
Vanderborght expt 3 & $\Omega=$ soil & $1.16 \times 10^{-8}$ & $1.16 \times 10^{-8}$ \\
Wigmosta expt 1 & $\Omega=$ soil & $4.73 \times 10^{-5}$ & $9.42 \times 10^{-6}$ \\
Wigmosta expt 2 & $\Omega=$ soil & $5.40 \times 10^{-5}$ & $1.38 \times 10^{-5}$ \\
Colbeck expt 1 & $\Omega=$ snow & $1.64 \times 10^{-12}$ & $3.66 \times 10^{-15}$ \\
Colbeck expt 2 & $\Omega=$ snow & $8.76 \times 10^{-14}$ & $9.92 \times 10^{-16}$ \\
Colbeck expt 3 & $\Omega=$ snow & $4.22 \times 10^{-15}$ & $4.72 \times 10^{-16}$ \\
Mizoguchi & $\Omega=$ soil & $1.90 \times 10^{-14}$ & $2.39 \times 10^{-16}$ \\
\hline
\end{tabular}

$$
\varepsilon_{\text {mass }_{n}}^{\Omega}=\sum_{j=1}^{J^{\Omega}} \varepsilon_{\text {mass }_{j}, n}^{\Omega}
$$

The statistics of the mass balance errors are quantified in Table 7 using the maximum absolute mass balance error $\left\|\varepsilon_{\text {mass }}^{\Omega}\right\|_{\infty}=\max _{n}\left|\varepsilon_{\text {mass }_{n}}^{\Omega}\right|$ and the mean absolute mass balance error $\left\|\varepsilon_{\text {mass }}^{\Omega}\right\|_{1} / n=\sum_{n}\left|\varepsilon_{\text {mass }_{n}}^{\Omega}\right| / n$.

\section{Data availability}

Results for all six synthetic test cases are available on https:// github.com/CH-Earth/laughTests. The repository includes both simulations of the test cases from SUMMA/SUNDIALS as well as the Python code (in the form of Jupyter notebooks) that was used to read the SUMMA/SUNDIALS output and generate Figs. 2-8 in this paper. The analytical solutions (for the Vanderborght, Wigmosta, and Colbeck test cases) as well as the laboratory data (Mizoguchi test case) needed for comparison with the model outputs are included in these notebooks.

We expect that the SUMMA/SUNDIALS solutions will be useful for other model development groups because we ensure that the SUMMA/SUNDIALS solutions satisfy prescribed error tolerances (i.e., we have quantitative evidence that our numerical solutions are correct). The availability of the SUMMA/SUNDIALS solutions enables different modeling groups to use these solutions in their own model development work and publications. For example, it is possible for authors to compare their numerical solutions against the numerical solutions from SUMMA/SUNDIALS. Land model users and developers are invited to extend laugh test applications beyond the collection of tests presented in this paper.

\section{Summary and discussion}

The intent of this paper is to encourage improved numerical implementation of land models. Our contributions in this paper are twofold. First, we present a unified framework to 
formulate and implement land model equations. We separate the representation of physical processes from their numerical solution, enabling the use of established robust numerical methods to solve the model equations. Second, we introduce a set of synthetic test cases (the laugh tests) to evaluate the numerical implementation of land models. The test cases include storage and transmission of water in soils, lateral subsurface flow, coupled hydrological and thermodynamic processes in snow, and cryosuction processes in soil. We consider synthetic test cases as laugh tests for land models because they provide the most rudimentary test of model capabilities.

The results presented in this paper give solutions to all of the test cases using the SUNDIALS solver (Hindmarsh et al. 2005) implemented in the SUMMA model (Clark et al. 2015b). The numerical simulations from SUMMA/SUNDIALS are compared against 1) solutions to the synthetic test cases from other models documented in the peer-reviewed literature (for infiltration into initially dry soil); 2) analytical solutions (for the steady-state flux in layered soil, lateral flow across a hillslope, and coupling of thermodynamic and hydrological processes in snow); and 3) observations made in laboratory experiments (for cryosuction processes in soil). In all cases, the numerical simulations are similar to the benchmarks, building confidence in the numerical model implementation.

We posit that some land models may have difficulty in solving these benchmark problems. For example, land models often implement the moisture-based form of Richards' equation and hence do not have the capabilities to simulate variably saturated flow, making it impossible to solve the Miller test cases presented. Moreover, the simplistic implementation of Richards' equation in land models, e.g., noniterative solutions of the moisture-based form of Richards' equation that require ad hoc numerical "fixes" (Clark et al. 2015a), can also create challenges to effectively solve the test case of Celia et al. of infiltration into initially dry soil and the Vanderborght test case for steady-state flux in layered soil. Land models do not typically include the lateral flow across soil columns and hence may not have the capability to solve the Wigmosta test case. More generally, land models may not adequately couple the thermodynamic and hydrological processes, creating challenges to simulate the Colbeck rainon-snow test case and the Mizoguchi cryosuction experiments. Dedicating more effort to solving synthetic test cases is critical in order to determine when land models are suitable for specific applications.

The synthetic test cases presented here should become an integral part of broader efforts to evaluate the numerical implementation of land models across large geographical domains (i.e., a river basin, a continent, the globe). First, the laugh tests should be used with a very fine spatial discretization that limits numerical approximation errors (as shown in this paper) to confirm that model equations were implemented and solved correctly. Next, it is critical to carefully analyze accuracyefficiency tradeoffs in order to optimize land model configurations. Large-domain applications of land models typically require accepting some numerical simplifications, for example, accepting numerical errors that arise from a spatial (vertical) discretization that is too coarse and accepting numerical errors that arise from time steps that are too long. The analysis of accuracy-efficiency tradeoffs enable us to complete largedomain model simulations with full awareness of any numerical errors that we introduce.

More work is also needed to extend the laugh tests to include a more extensive set of biophysical and biogeochemical processes. The test cases presented here are limited in that they only evaluate a small subset of processes in land models. More test cases are needed that evaluate some of the processes that are neglected in this study (e.g., biophysical processes such as evapotranspiration). We encourage the community to continue to collect and define laugh tests such as these so that laugh tests become a critical plank in comprehensive benchmarking platforms.

Acknowledgments. This work was supported by the Global Water Futures programme in Canada. We greatly appreciate the constructive comments from the three reviewers.

\section{APPENDIX A}

\section{Implicit Euler Solutions}

The numerical solvers in land models are generally much simpler than those in IDA; most land models use some variant of a first-order implicit Euler approximation over long time steps. Specifically, the nonlinear equations are typically solved using Newton-Raphson iteration, where every iteration consists of solving the linear system in Eq. (A1) followed by the update in Eq. (A1):

$$
\begin{aligned}
\mathbf{J}_{n+1}^{(\ell)} \delta \boldsymbol{\zeta}_{n+1}^{(\ell+1)} & =-\mathbf{r}_{n+1}^{(\ell)}, \\
\boldsymbol{\zeta}_{n+1}^{(\ell+1)} & =\boldsymbol{\zeta}_{n+1}^{(\ell)}+\delta \boldsymbol{\zeta}_{n+1}^{(\ell+1)},
\end{aligned}
$$

where the superscript $\ell$ indexes the nonlinear solver iterations, the subscript $n$ indexes the time step, $\zeta$ is the model state vector, $\mathbf{r}$ is the error (in this case, the residual in the energy and mass balance over the time step), and $\mathbf{J}$ is the Jacobian matrix.

A straightforward solution to conserve energy and mass in land models is to use finite differences for the residual in Eq. (A1) and analytical derivatives for the Jacobian matrix. Note that the solution at convergence does not depend on the analytical derivatives because $\mathbf{J}_{n+1}^{(\ell)} \delta \boldsymbol{\zeta}_{n+1}^{(\ell+1)} \rightarrow 0$ at convergence [see, e.g., Rathfelder and Abriola (1994) for a discussion of mass-conservative solutions of Richards' equation].

\section{a. Implicit Euler solutions for thermodynamics}

An energy-conserving solution of Eq. (1) can be derived starting with the implicit Euler discretization of Eq. (45):

$$
\tilde{C}_{p_{j}}^{\Omega} \frac{\Delta T_{j, n+1}^{\Omega}}{\Delta t_{n}}-L_{\text {fus }} \rho_{\text {ice }} \frac{\Delta \theta_{\text {ice }_{j, n+1}}^{\Omega}}{\Delta t_{n}}=F_{\text {net }_{j, n+1}}^{\Omega},
$$

where $\Delta T_{j, n+1}^{\Omega}=\left[T_{j}^{\Omega}\left(t_{n+1}\right)-T_{j}^{\Omega}\left(t_{n}\right)\right]$ and $\Delta \theta_{\text {ice }_{j, n+1}}^{\Omega}=\left[\theta_{\text {ice }_{j}}^{\Omega}\left(t_{n+1}\right)-\right.$ $\left.\theta_{\text {ice }_{j}}^{\Omega}\left(t_{n}\right)\right]$ are respectively the change in temperature $(\mathrm{K})$ and volumetric ice content (-) over the time interval $\left[t_{n}, t_{n+} 1\right]$. In Eq. (A3), $F_{\text {net }_{j}}^{\Omega}$ is computed using Eq. (42). 
Given the energy conservation condition $\tilde{C}_{p_{j}} \Delta T_{j, n+1}^{\Omega}=$ $\Delta H_{j, n+1}^{\Omega}$ and making use of Eq. (8), the time differences for the heat and phase change terms on the LHS of Eq. (A3) can be expanded as

$$
\begin{aligned}
& \Delta H_{T_{j, n+1}}^{\Omega(\ell+1)}=\Delta H_{T_{j, n+1}}^{\Omega(\ell)}+\left(\frac{d H_{T_{j, n+1}}^{\Omega}}{d T_{j, n+1}^{\Omega}}\right)^{(\ell)} \delta T_{j, n+1}^{\Omega(\ell+1)}, \\
& \Delta \theta_{\text {ice }_{j, n+1}(\ell+1)}^{\Omega(\ell)}=\Delta \theta_{\mathrm{ice}_{j, n+1}}^{\Omega(\ell)}+\left(\frac{d \theta_{\mathrm{ic}_{j, n+1}}^{\Omega}}{d T_{j, n+1}^{\Omega}}\right)^{(\ell)} \delta T_{j, n+1}^{\Omega(\ell+1)},
\end{aligned}
$$

where $H_{T}^{\Omega}$ is defined in Eqs. (3), (4), and (9) and

$$
\begin{gathered}
\Delta H_{T_{j, n+1}}^{\Omega(\ell)}=H_{T_{j, n+1}}^{\Omega(\ell)}-H_{T_{j, n}}^{\Omega}, \\
\Delta \theta_{\mathrm{ice}_{j, n+1}(\ell)}^{\Omega\left({ }^{2}\right.}=\theta_{\mathrm{ice}_{j, n+1}}^{\Omega(\ell)}-\theta_{\mathrm{ice}_{j, n},}^{\Omega}, \\
\delta T_{j, n+1}^{\Omega(\ell+1)}=T_{j, n+1}^{\Omega(\ell+1)}-T_{j, n+1}^{\Omega(\ell)} .
\end{gathered}
$$

with

$$
\begin{aligned}
\Delta \Theta_{m_{j, n+1}}^{\mathrm{soil}(\ell)} & =\Theta_{m_{j, n+1}}^{\mathrm{soil}(\ell)}-\Theta_{m_{j, n}}^{\mathrm{soil}}, \\
\delta \psi_{0_{j, n+1}}^{(\ell+1)} & =\psi_{0_{j, n+1}}^{(\ell+1)}-\psi_{0_{j, n+1}}^{(\ell)} .
\end{aligned}
$$

Combining Eqs. (15), (40), and (A7),

$$
\begin{aligned}
& {\left[S_{s} \frac{\Theta_{m_{j, n+1}}^{\text {soil }(\ell)}}{\theta_{s_{j}}}+\left(\frac{d \Theta_{m_{j, n+1}}^{\text {soil }}}{d \psi_{0_{j, n+1}}}\right)^{(\ell)}-\Delta t_{n}\left(\frac{d q_{\mathrm{net}_{j, n+1}}^{\text {soil }}}{d \psi_{0_{j, n+1}}}\right)^{(\ell)}\right] \delta \psi_{0_{j, n+1}}^{(\ell+1)}} \\
& =\Delta t_{n}\left(q_{\text {net }_{j, n+1}}^{\text {soil }}+S_{\text {sink }_{j, n+1}}^{\text {soil }}\right)^{(\ell)}-S_{s} \frac{\Theta_{m_{j, n+1}}^{\text {soil }(\ell)}}{\theta_{s_{j}}} \Delta \psi_{0_{j, n+1}}^{(\ell)}-\Delta \Theta_{m_{j, n+1}}^{\text {soil }(\ell)}
\end{aligned}
$$

In Eq. (A9), $\Theta_{m}^{\text {soil }}$ is a diagnostic variable computed from $\psi_{0}$.

\section{APPENDIX B}

\section{Enthalpy Calculations}

from Eq. (11) that $d H_{T}^{\Omega} / d T^{\Omega}=C_{p}^{\Omega}$

Given the definition of $C_{a}^{\Omega}$ in Eq. (13) and noting that $C_{a}^{\Omega}=d H^{\Omega} / d T^{\Omega}$, an implicit finite difference discretization of the heat equation in Eqs. (1), (8), (10), and (12) can be defined as

$$
\begin{aligned}
& {\left[C_{a_{j, n+1}}^{\Omega(\ell)}-\Delta t_{n}\left(\frac{d F_{\mathrm{net}_{j, n+1}}^{\Omega}}{d T_{j, n+1}^{\Omega}}\right)^{(\ell)}\right] \delta T_{j, n+1}^{\Omega(\ell+1)}=\Delta t_{n} F_{\mathrm{net}_{j, n+1}}^{\Omega(\ell)}-\Delta H_{T_{j, n+1}}^{\Omega(\ell)}} \\
& +L_{\text {fus }} \rho_{\text {ice }} \Delta \theta_{\mathrm{ice}_{j, n+1}}^{\Omega(\ell)} .
\end{aligned}
$$

In Eq. (A6), the enthalpy $H_{T}^{\Omega}$ and volumetric ice content $\theta_{\text {ice }}^{\Omega}$ are both diagnostic variables. See appendix B for the methods used to calculate enthalpy, Eqs. (7) and (62) for methods to calculate $\theta_{\text {ice }}^{\text {snow }}\left(T^{\text {snow }}, \Theta_{m}^{\text {snow }}\right)$, and Eqs. (67)-(73) to calculate $\theta_{\text {ice }}^{\text {soil }}\left(T^{\text {soil }}, \psi_{0}\right)$.

\section{b. Implicit Euler solutions for soil hydrology}

A mass-conserving solution for soil hydrology is the mixed formulation of Richards' equation described by Celia et al. (1990). Starting with the implicit Euler discretization of Eqs. (15), (40), and (49),

$$
\begin{aligned}
S_{s} \frac{\Theta_{m_{j, n+1}}^{\text {soil }}}{\theta_{s_{j}}} \frac{\Delta \psi_{0_{j, n+1}}}{\Delta t_{n}}+\tilde{C}_{\psi_{j, n+1}}^{\text {soil }} \frac{\Delta \psi_{0_{j, n+1}}}{\Delta t_{n}} & =q_{\text {net }_{j, n+1}}^{\text {soil }}+\mathcal{M}_{\text {sink }_{j, n+1}}^{\text {soil }}, \\
j & =1,2, \ldots, J^{\text {soil }},
\end{aligned}
$$

where $\tilde{C}_{\psi}^{\text {soil }}=d \Theta_{\mathrm{m}}^{\text {soil }} / d \psi_{0}$ and $q_{\text {net }}^{\text {soil }}$ is computed in Eq. (47). In Eq. (A7), $\Delta \psi_{0_{i, n+1}}=\left[\psi_{0_{j}}\left(t_{n+1}\right)-\psi_{0_{j}}\left(t_{n}\right)\right]$ can be expanded as

$$
\Delta \psi_{0_{j, n+1}}^{(\ell+1)}=\Delta \Theta_{m_{j, n+1}}^{\mathrm{soil}(\ell)}+\left(\frac{d \Theta_{\mathrm{m}_{j, n+1}}^{\text {soil }}}{d \psi_{0_{j, n+1}}}\right)^{(\ell)} \delta \psi_{0_{j, n+1}}^{(\ell+1)},
$$

\section{a. The snow domain} and (4):

$$
\begin{aligned}
H^{\text {snow }}= & H_{T, \text { liq }}^{\text {snow }}+H_{T, \text { ice }}^{\text {snow }}+H_{T, \text { air }}^{\text {snow }}-L_{\text {fus }} \rho_{\text {ice }}\left[\theta_{\text {ice }}^{\text {snow }}\left(T^{\text {snow }}\right)\right. \\
& \left.-\theta_{\text {ice }}^{\text {snow }}\left(T_{\text {ref }}\right)\right] .
\end{aligned}
$$

Given Eq. (4) and $T_{\text {ref }}=T_{\text {frz }}$,

$$
\begin{aligned}
H_{T, \text { liq }}^{\text {snow }}+H_{T, \text { ice }}^{\text {snow }} & =c_{\text {liq }} \int_{T_{\text {frz }}}^{T_{\text {liq }}^{\text {snow }}} \rho_{\text {liq }} \theta_{\text {liq }}^{\text {snow }} d T+c_{\text {ice }} \int_{T_{\text {frz }}}^{T_{\text {snow }}^{\text {sno }}} \rho_{\text {ice }} \theta_{\text {ice }}^{\text {snow }} d T \\
& =\rho_{\text {liq }} \int_{T_{\text {frz }}}^{T_{\text {snow }}}\left[c_{\text {ice }}\left(\Theta_{\mathrm{m}}^{\text {snow }}-\theta_{\text {ice }}^{\text {snow }}\right)+c_{\text {liq }} \theta_{\text {liq }}^{\text {snow }}\right] d T,
\end{aligned}
$$

and making use of Eq. (62) to compute $\theta_{\text {liq }}^{\text {snow }}$,

$$
\begin{aligned}
H_{T, \text { liq }}^{\text {snow }}+H_{T, \text { ice }}^{\text {snow }} & =\rho_{\text {liq }} \Theta_{m}^{\text {snow }} \int_{T_{\text {frz }}}^{T_{\text {ice }}^{\text {snow }}} c_{\text {ic }}+\frac{c_{\text {liq }}-c_{\text {ice }}}{1+\left[\varpi\left(T_{\text {frz }}-T\right)\right]^{2}} d T \\
& =\rho_{\text {liq }} \Theta_{m}^{\text {snow }}\left[\operatorname{atan}(\varpi \delta T) \frac{c_{\text {liq }}-c_{\text {ice }}}{\varpi}+c_{\text {ice }} \delta T\right],
\end{aligned}
$$

where $\delta T=T^{\text {snow }}-T_{\mathrm{frz}}$. We note that these equations are only developed for $T<T_{\text {frz }}$ because snow cannot exist at temperatures above freezing-i.e., in Eq. (62), all water is liquid when $T>T_{\text {frz }}$.
The mixture enthalpy for snow, $H^{\text {snow }}$, is given from Eqs. (3) 


\section{b. The soil domain}

The mixture enthalpy for soil, $H^{\text {soil }}$, is also given from Eqs. (3) and (4). From Eq. (3),

$$
\begin{aligned}
H^{\text {soil }}= & H_{T, \text { soil }}^{\text {soil }}+H_{T, \text { liq }}^{\text {soil }}+H_{T, \text { ice }}^{\text {soil }}+H_{T, \text { air }}^{\text {soil }} \\
& -L_{\text {fus }} \rho_{\text {ice }}\left[\theta_{\text {ice }}^{\text {soil }}\left(T^{\text {soil }}\right)-\theta_{\text {ice }}^{\text {soil }}\left(T_{\text {ref }}\right)\right],
\end{aligned}
$$

where enthalpies of the constituents are computed using Eqs. (4) and (71)-(73). Starting by assuming saturated conditions, i.e., $\psi_{0} \geq 0$, and setting $T_{\text {ref }}=T_{\text {frz }}$, Eq. (4) can be written as

$$
\mathcal{H}\left(T^{\text {soil }}\right)=\int_{T_{\text {frz }}}^{T_{\text {sil }}^{\text {soil }}}\left[c_{\text {liq }} \rho_{\text {liq }} \theta_{\text {liq }}^{\text {soil }}(T)+c_{\text {ice }} \rho_{\text {ice }} \theta_{\text {ice }}^{\text {soil }}(T)\right] d T,
$$

noting that under saturated conditions

$$
\begin{aligned}
& \theta_{\text {liq }}^{\text {soil }}\left(T^{\text {soil }}\right)=S_{*}\left(\psi_{c}\right)=S_{*}\left(\frac{L_{\text {fus }}}{g} \frac{T^{\text {soil }}-T_{\text {frz }}}{T_{\text {frz }}}\right), \\
& \theta_{\text {ice }}^{\text {soil }}\left(T^{\text {soil }}\right)=\theta_{s}-\theta_{\text {liq }}^{\text {soil }}\left(T^{\text {soil }}\right) .
\end{aligned}
$$

The enthalpy for variably saturated soil can then be computed by making use of Eqs. (71)-(73),

$$
H_{T, \text { liq }}^{\text {soil }}+H_{T, \text { ice }}^{\text {soil }}=\left\{\begin{array}{cl}
{\left[\mathcal{H}\left(T^{\text {soil }}\right)-\mathcal{H}\left(T_{*}\right)\right]+c_{\text {liq }} \rho_{\text {liq }} S_{*}\left(\psi_{0}\right)\left(T^{\text {soil }}-T_{*}\right),} & T^{\text {soil }}<T_{*}, \\
c_{\text {liq }} \rho_{\text {liq }} S_{*}\left(\psi_{0}\right)\left(T^{\text {soil }}-T_{*}\right), & T^{\text {soil }} \geq T_{*},
\end{array}\right.
$$

noting from Eq. (70) that $T_{*}$ is the temperature where all water is unfrozen. In the test cases examined here, $\mathcal{H}(\cdot)$ is computed by fitting a cubic spline to a lookup table of $T^{\text {soil }}$ and $H^{\text {soil }}$ values.

\section{REFERENCES}

Baldocchi, D. D., and K. B. Wilson, 2001: Modeling $\mathrm{CO}_{2}$ and water vapor exchange of a temperate broadleaved forest across hourly to decadal time scales. Ecol. Modell., 142, 155-184, https://doi.org/10.1016/S0304-3800(01)00287-3.

Balsamo, G., F. Pappenberger, E. Dutra, P. Viterbo, and B. Van den Hurk, 2011: A revised land hydrology in the ECMWF model: A step towards daily water flux prediction in a fullyclosed water cycle. Hydrol. Processes, 25, 1046-1054, https:// doi.org/10.1002/hyp.7808.

Bao, H., T. Koike, K. Yang, L. Wang, M. Shrestha, and P. Lawford, 2016: Development of an enthalpy-based frozen soil model and its validation in a cold region in China. J. Geophys. Res. Atmos., 121, 5259-5280, https://doi.org/10.1002/2015JD024451.

Bisht, G., and W. J. Riley, 2019: Development and verification of a numerical library for solving global terrestrial multiphysics problems. J. Adv. Model. Earth Syst., 11, 1516-1542, https:// doi.org/10.1029/2018MS001560.

Bogaart, P. W., D. E. Rupp, J. S. Selker, and Y. van derVelde, 2013: Late-time drainage from a sloping Boussinesq aquifer. Water Resour. Res., 49, 7498-7507, https://doi.org/10.1002/ 2013WR013780.

Bonan, G., M. Williams, R. Fisher, and K. Oleson, 2014: Modeling stomatal conductance in the Earth system: Linking leaf water-use efficiency and water transport along the soilplant-atmosphere continuum. Geosci. Model Dev., 7, 21932222, https://doi.org/10.5194/gmd-7-2193-2014.

Bonan, G. B., E. G. Patton, I. N. Harman, K. W. Oleson, J. J. Finnigan, Y. Lu, and E. A. Burakowski, 2018: Modeling canopy-induced turbulence in the earth system: A unified parameterization of turbulent exchange within plant canopies and the roughness sublayer (CLM-ml v0). Geosci. Model Dev., 11, 1467-1496, https://doi.org/10.5194/gmd-111467-2018.

Boone, A., and P. Wetzel, 1996: Issues related to low resolution modeling of soil moisture: Experience with the PLACE model. Global Planet. Change, 13, 161-181, https://doi.org/ 10.1016/0921-8181(95)00044-5.
Bowling, L. C., and D. P. Lettenmaier, 2010: Modeling the effects of lakes and wetlands on the water balance of arctic environments. J. Hydrometeor., 11, 276-295, https://doi.org/10.1175/ 2009JHM1084.1.

Celia, M., E. Bouloutas, and R. Zabra, 1990: A general massconservative numerical-solution for the unsaturated flow equation. Water Resour. Res., 26, 1483-1496, https://doi.org/ 10.1029/WR026i007p01483.

Chaney, N. W., M. H. J. Van Huijgevoort, E. Shevliakova, S. Malyshev, P. C. D. Milly, P. P. G. Gauthier, and B. N. Sulman, 2018: Harnessing big data to rethink land heterogeneity in Earth system models. Hydrol. Earth Syst. Sci., 22, 3311-3330, https://doi.org/10.5194/hess-22-3311-2018.

Clark, M. P., D. Kavetski, and F. Fenicia, 2011: Pursuing the method of multiple working hypotheses for hydrological modeling. Water Resour. Res., 47, W09301, https://doi.org/10.1029/2010WR009827.

— drologic processes in Earth system models. Water Resour. Res., 51, 5929-5956, https://doi.org/10.1002/2015WR017096.

_ , and Coauthors, 2015b: A unified approach for process-based hydrologic modeling: 1. Modeling concept. Water Resour. Res., 51, 2498-2514, https://doi.org/10.1002/2015WR017198.

, and Coauthors, 2015c: A unified approach for process-based hydrologic modeling: 2. Model implementation and case studies. Water Resour. Res., 51, 2515-2542, https://doi.org/ 10.1002/2015WR017200.

_- B. Nijssen, and C. H. Luce, 2017: An analytical test case for snow models. Water Resour. Res., 53, 909-922, https://doi.org/ 10.1002/2016WR019672.

Clow, G. D., 2018: CVPM 1.1: A flexible heat-transfer modeling system for permafrost. Geosci. Model Dev., 11, 4889-4908, https://doi.org/10.5194/gmd-11-4889-2018.

Colbeck, S., 1976: Analysis of water-flow in dry snow. Water Resour. Res., 12, 523-527, https://doi.org/10.1029/WR012i003p00523.

Coon, E. T., J. D. Moulton, and S. L. Painter, 2016: Managing complexity in simulations of land surface and near-surface processes. Environ. Modell. Software, 78, 134-149, https:// doi.org/10.1016/j.envsoft.2015.12.017.

Dai, Y., R. E. Dickinson, and Y.-P. Wang, 2004: A two-big-leaf model for canopy temperature, photosynthesis, and stomatal conductance. J. Climate, 17, 2281-2299, https://doi.org/10.1175/ 1520-0442(2004)017<2281:ATMFCT>2.0.CO;2.

Dall'Amico, M., S. Endrizzi, S. Gruber, and R. Rigon, 2011: A robust and energy-conserving model of freezing variably-saturated 
soil. Cryosphere, 5, 469-484, https://doi.org/10.5194/tc-5469-2011.

Duan, J., and N. Miller, 1997: A generalized power function for the subsurface transmissivity profile in TOPMODEL. Water Resour. Res., 33, 2559-2562, https://doi.org/10.1029/ 97WR02186.

Fan, Y., and G. Miguez-Macho, 2011: A simple hydrologic framework for simulating wetlands in climate and Earth system models. Climate Dyn., 37, 253-278, https://doi.org/ 10.1007/s00382-010-0829-8.

— , and Coauthors, 2019: Hillslope hydrology in global change research and earth system modeling. Water Resour. Res., 55, 1737-1772, https://doi.org/10.1029/2018WR023903.

Fatichi, S., and Coauthors, 2016: An overview of current applications, challenges, and future trends in distributed processbased models in hydrology. J. Hydrol., 537, 45-60, https:// doi.org/10.1016/j.jhydrol.2016.03.026.

Fisher, R. A., and C. D. Koven, 2020: Perspectives on the future of land surface models and the challenges of representing complex terrestrial systems. J. Adv. Model. Earth Syst., 12, e2018MS001453, https://doi.org/10.1029/2018MS001453.

Flerchinger, G., W. Kustas, and M. Weltz, 1998: Simulating surface energy fluxes and radiometric surface temperatures for two arid vegetation communities using the SHAW model. J. Appl. Meteor., 37, 449-460, https://doi.org/10.1175/1520-0450(1998) $037<0449:$ SSEFAR $>2.0 . \mathrm{CO} ; 2$.

Govindaraju, R., M. Kavvas, and S. Jones, 1990: Approximate analytical solutions for overland flows. Water Resour. Res., 26, 2903-2912, https://doi.org/10.1029/WR026i012p02903.

Grenier, C., and Coauthors, 2018: Groundwater flow and heat transport for systems undergoing freeze-thaw: Intercomparison of numerical simulators for 2D test cases. Adv. Water Resour., 114, 196-218, https://doi.org/10.1016/j.advwatres.2018.02.001.

Hansson, K., J. Simunek, M. Mizoguchi, L. Lundin, and M. van Genuchten, 2004: Water flow and heat transport in frozen soil: Numerical solution and freeze-thaw applications. Vadose Zone J., 3, 693-704, https://doi.org/10.2136/vzj2004.0693.

Harlan, R., 1973: Analysis of coupled heat-fluid transport in partially frozen soil. Water Resour. Res., 9, 1314-1323, https:// doi.org/10.1029/WR009i005p01314.

Hindmarsh, A. C., P. N. Brown, K. E. Grant, S. L. Lee, R. Serban, D. E. Shumaker, and C. S. Woodward, 2005: Sundials: Suite of nonlinear and differential/algebraic equation solvers. $A C M$ Trans. Math. Software, 31, 363-396, https://doi.org/10.1145/ 1089014.1089020.

Karra, S., S. Painter, and P. Lichtner, 2014: Three-phase numerical model for subsurface hydrology in permafrost-affected regions (PFLOTRAN-ICE v1. 0). Cryosphere, 8, 1935-1950, https://doi.org/10.5194/tc-8-1935-2014.

Kavetski, D., P. Binning, and S. Sloan, 2001: Adaptive time stepping and error control in a mass conservative numerical solution of the mixed form of Richards equation. Adv. Water Resour., 24, 595-605, https://doi.org/10.1016/S0309-1708(00) 00076-2.

Koren, V., J. Schaake, K. Mitchell, Q.-Y. Duan, F. Chen, and J. Baker, 1999: A parameterization of snowpack and frozen ground intended for NCEP weather and climate models. J. Geophys. Res., 104, 19569-19 585, https://doi.org/10.1029/ 1999JD900232.

Kurylyk, B. L., J. M. McKenzie, K. T. MacQuarrie, and C. I. Voss, 2014: Analytical solutions for benchmarking cold regions subsurface water flow and energy transport models: Onedimensional soil thaw with conduction and advection.
Adv. Water Resour., 70, 172-184, https://doi.org/10.1016/ j.advwatres.2014.05.005.

Lawrence, D. M., and Coauthors, 2019: The community land model version 5: Description of new features, benchmarking, and impact of forcing uncertainty. J. Adv. Model. Earth Syst., 11, 4245-4287, https://doi.org/10.1029/2018MS001583.

Lee, D., and L. Abriola, 1999: Use of the Richards equation in land surface parameterizations. J. Geophys. Res., 104, 27519 27 526, https://doi.org/10.1029/1999JD900951.

Li, H., M. S. Wigmosta, H. Wu, M. Huang, Y. Ke, A. M. Coleman, and L. R. Leung, 2013: A physically based runoff routing model for land surface and Earth system models. J. Hydrometeor., 14, 808-828, https://doi.org/10.1175/JHM-D-12-015.1.

Mackay, D. S., D. E. Roberts, B. E. Ewers, J. S. Sperry, N. G. McDowell, and W. T. Pockman, 2015: Interdependence of chronic hydraulic dysfunction and canopy processes can improve integrated models of tree response to drought. Water Resour. Res., 51, 6156-6176, https://doi.org/10.1002/ 2015WR017244.

Marsh, C. B., R. J. Spiteri, J. W. Pomeroy, and H. S. Wheater, 2018: Multi-objective unstructured triangular mesh generation for use in hydrological and land surface models. Comput. Geosci., 119, 49-67, https://doi.org/10.1016/j.cageo.2018.06.009.

Maxwell, R. M., and Coauthors, 2014: Surface-subsurface model intercomparison: A first set of benchmark results to diagnose integrated hydrology and feedbacks. Water Resour. Res., 50, 1531-1549, https://doi.org/10.1002/2013WR013725.

Melton, J. R., V. K. Arora, E. Wisernig-Cojoc, C. Seiler, M. Fortier, E. Chan, and L. Teckentrup, 2020: Classic v1. 0: The opensource community successor to the Canadian Land Surface Scheme (CLASS) and the Canadian Terrestrial Ecosystem Model (CTEM)-Part 1: Model framework and site-level performance. Geosci. Model Dev., 13, 2825-2850, https://doi.org/ 10.5194/gmd-13-2825-2020.

Miguez-Macho, G., and Y. Fan, 2012: The role of groundwater in the Amazon water cycle: 1. Influence on seasonal streamflow, flooding and wetlands. J. Geophys. Res., 117, D15113, https:// doi.org/10.1029/2012JD017539.

Miller, C., G. Williams, C. Kelley, and M. Tocci, 1998: Robust solution of Richards' equation for nonuniform porous media. Water Resour. Res., 34, 2599-2610, https://doi.org/10.1029/ 98WR01673.

_ C. Abhishek, and M. Farthing, 2006: A spatially and temporally adaptive solution of Richards' equation. Adv. Water Resour., 29, 525-545, https://doi.org/10.1016/j.advwatres.2005.06.008.

Milly, P., 1984: A mass-conservative procedure for time-stepping in models of unsaturated flow. Finite Elements in Water Resources, Springer, 103-112.

Mizoguchi, M., 1990: Water, heat and salt transport in freezing soil. Ph.D. thesis, University of Tokyo, 216 pp.

Mizumura, K., 2006: Analytical solutions of nonlinear kinematic wave model. J. Hydrol. Eng., 11, 539-546, https://doi.org/ 10.1061/(ASCE)1084-0699(2006)11:6(539).

_ wave model with time-varying rainfall. J. Hydrol. Eng., 16, 736745, https://doi.org/10.1061/(ASCE)HE.1943-5584.0000365.

— flow of an open book type using kinematic wave. J. Hydrol. Eng., 16, 926-934, https://doi.org/10.1061/(ASCE)HE.19435584.0000398 .

Nedjar, B., 2002: An enthalpy-based finite element method for nonlinear heat problems involving phase change. Comput. Struc., 80, 9-21, https://doi.org/10.1016/S0045-7949(01)00165-1. 
Noh, J.-H., S.-R. Lee, and H. Park, 2012: Prediction of cryoSWCC during freezing based on pore-size distribution. Int. J. Geomech., 12, 428-438, https://doi.org/10.1061/(ASCE) GM.1943-5622.0000134.

Painter, S. L., 2011: Three-phase numerical model of water migration in partially frozen geological media: Model formulation, validation, and applications. Comput. Geosci., 15, 69-85, https://doi.org/10.1007/s10596-010-9197-z.

_ content in subfreezing unsaturated soils. Vadose Zone J., 13, vzj2013.04.0071, https://doi.org/10.2136/vzj2013.04.0071.

Parlange, J., C. Rose, and G. Sander, 1981: Kinematic flow approximation of runoff on a plane: An exact analytical solution. J. Hydrol., 52, 171-176, https://doi.org/10.1016/0022-1694(81) 90104-9.

Peters-Lidard, C. D., and Coauthors, 2017: Scaling, similarity, and the fourth paradigm for hydrology. Hydrol. Earth Syst. Sci., 21, 3701-3713, https://doi.org/10.5194/hess-21-3701-2017.

Rathfelder, K., and L. M. Abriola, 1994: Mass conservative numerical solutions of the head-based Richards equation. Water Resour. Res., 30, 2579-2586, https://doi.org/10.1029/94WR01302.

Rupp, D. E., and J. S. Selker, 2005: Drainage of a horizontal Boussinesq aquifer with a power law hydraulic conductivity profile. Water Resour. Res., 41, W11422, https://doi.org/10.1029/ 2005 WR004241.

— , and — 2006: On the use of the Boussinesq equation for interpreting recession hydrographs from sloping aquifers. Water Resour. Res., 42, W12421, https://doi.org/10.1029/ 2006WR005080.

_ modelling using a power law transmissivity profile. Hydrol. Processes, 22, 2667-2671, https://doi.org/10.1002/hyp.6863.

Spaans, E. J., and J. M. Baker, 1996: The soil freezing characteristic: Its measurement and similarity to the soil moisture characteristic. Soil. Sci. Soc. Amer. J., 60, 13-19, https:// doi.org/10.2136/sssaj1996.03615995006000010005x.

Swenson, S. C., M. Clark, Y. Fan, D. M. Lawrence, and J. Perket, 2019: Representing intrahillslope lateral subsurface flow in the community land model. J. Adv. Model. Earth Syst., 11, 40444065, https://doi.org/10.1029/2019MS001833.

Tague, C., and L. Band, 2004: Rhessys: Regional hydro-ecologic simulation system-An object-oriented approach to spatially distributed modeling of carbon, water, and nutrient cycling. Earth Interact., 8, https://doi.org/10.1175/1087-3562(2004)8<1: RRHSSO $>2.0 . \mathrm{CO} ; 2$.

Tocci, M., C. Kelley, and C. Miller, 1997: Accurate and economical solution of the pressure-head form of Richards' equation by the method of lines. Adv. Water Resour., 20, 1-14, https:// doi.org/10.1016/S0309-1708(96)00008-5.

Tubini, N., S. Gruber, and R. Rigon, 2020: A method for solving heat transfer with phase change in ice or soil that allows for large time steps while guaranteeing energy conservation. Cryosphere Discuss., https://doi.org/10.5194/tc-2020-293.

Vanderborght, J., R. Kasteel, M. Herbst, M. Javaux, D. Thiery, M. Vanclooster, C. Mouvet, and H. Vereecken, 2005: A set of analytical benchmarks to test numerical models of flow and transport in soils. Vadose Zone J., 4, 206-221, https://doi.org/ 10.2136/vzj2005.0206.

van Genuchten, M. T., 1980: A closed-form equation for predicting the hydraulic conductivity of unsaturated soils. Soil. Sci. Soc. Amer. J., 44, 892-898, https://doi.org/10.2136/ sssaj1980.03615995004400050002x.

Voller, V. R., C. Swaminathan, and B. G. Thomas, 1990: Fixed grid techniques for phase change problems: A review. Int. J. Numer. Methods Eng., 30, 875-898, https://doi.org/10.1002/ nme.1620300419.

Wada, Y., D. Wisser, and M. F. Bierkens, 2014: Global modeling of withdrawal, allocation and consumptive use of surface water and groundwater resources. Earth Syst. Dyn., 5, 15-40, https:// doi.org/10.5194/esd-5-15-2014.

Walker, A. P., and Coauthors, 2015: Predicting long-term carbon sequestration in response to co2 enrichment: How and why do current ecosystem models differ? Global Biogeochem. Cycles, 29, 476-495, https://doi.org/10.1002/2014GB004995.

Wanders, N., S. Thober, R. Kumar, M. Pan, J. Sheffield, L. Samaniego, and E. F. Wood, 2019: Development and evaluation of a panEuropean multimodel seasonal hydrological forecasting system. J. Hydrometeor., 20, 99-115, https://doi.org/10.1175/ JHM-D-18-0040.1.

Wang, L., and Coauthors, 2017: Development of a land surface model with coupled snow and frozen soil physics. Water Resour. Res., 53, 5085-5103, https://doi.org/10.1002/2017WR020451.

Wigmosta, M., and D. Lettenmaier, 1999: A comparison of simplified methods for routing topographically driven subsurface flow. Water Resour. Res., 35, 255-264, https://doi.org/10.1029/ 1998WR900017.

_, L. Vail, and D. Lettenmaier, 1994: A distributed hydrologyvegetation model for complex terrain. Water Resour. Res., 30, 1665-1679, https://doi.org/10.1029/94WR00436.

Yigzaw, W., H.-Y. Li, X. Fang, L. R. Leung, N. Voisin, M. I. Hejazi, and Y. Demissie, 2019: A multilayer reservoir thermal stratification module for Earth system models. J. Adv. Model. Earth Syst., 11, 3265-3283, https://doi.org/10.1029/2019MS001632.

Zaehle, S., and A. Friend, 2010: Carbon and nitrogen cycle dynamics in the $\mathrm{O}-\mathrm{CN}$ land surface model: 1 . Model description, site-scale evaluation, and sensitivity to parameter estimates. Global Biogeochem. Cycles, 24, GB1005, https://doi.org/ 10.1029/2009GB003521.

Zhao, L., D. Gray, and D. Male, 1997: Numerical analysis of simultaneous heat and mass transfer during infiltration into frozen ground. J. Hydrol., 200, 345-363, https://doi.org/ 10.1016/S0022-1694(97)00028-0. 